Family Profile No. 18, 2020

\title{
Median Age at First Divorce, 2018
}

Author: Valerie Schweizer

The median age at first marriage has increased over the last few decades. In 1950, on average, women married at age 20 and men at age 22. By 2018, the average age had increased to 28 for women and 30 for men (FP-19-06). The counterpart to the median age at first marriage is the median age at first divorce, which has also risen despite overall declines in the U.S. divorce rate (FP-19-23). For more information on marriage and divorce rate trends, see FP-19-22 and FP-19-23. This profile uses the 2018 American Community Survey, 1-year estimates to examine the median age at first divorce for men and women by race/ethnicity and educational attainment, beginning with an overall trend figure comparing median ages at marriage and divorce for men and women. This profile is an update to FP-17-03.

\section{Median Ages at First Marriage and Divorce, 1970-2018}

- The median ages at first marriage and first divorce have been increasing for men and women since 1970. However, the median age at first divorce has risen more rapidly than the age at first marriage.

- A persistent gender gap characterizes the median age at first marriage and divorce, with men experiencing both events at older ages compared with women.

Figure 1. Median Ages at First Marriage and Divorce, 1970-2018

$-\rightarrow-$ Age at Divorce Men $\quad-\infty$ Age at Divorce Women $\quad--$ Age at Marriage Men $-\infty$ Age at Marriage Women

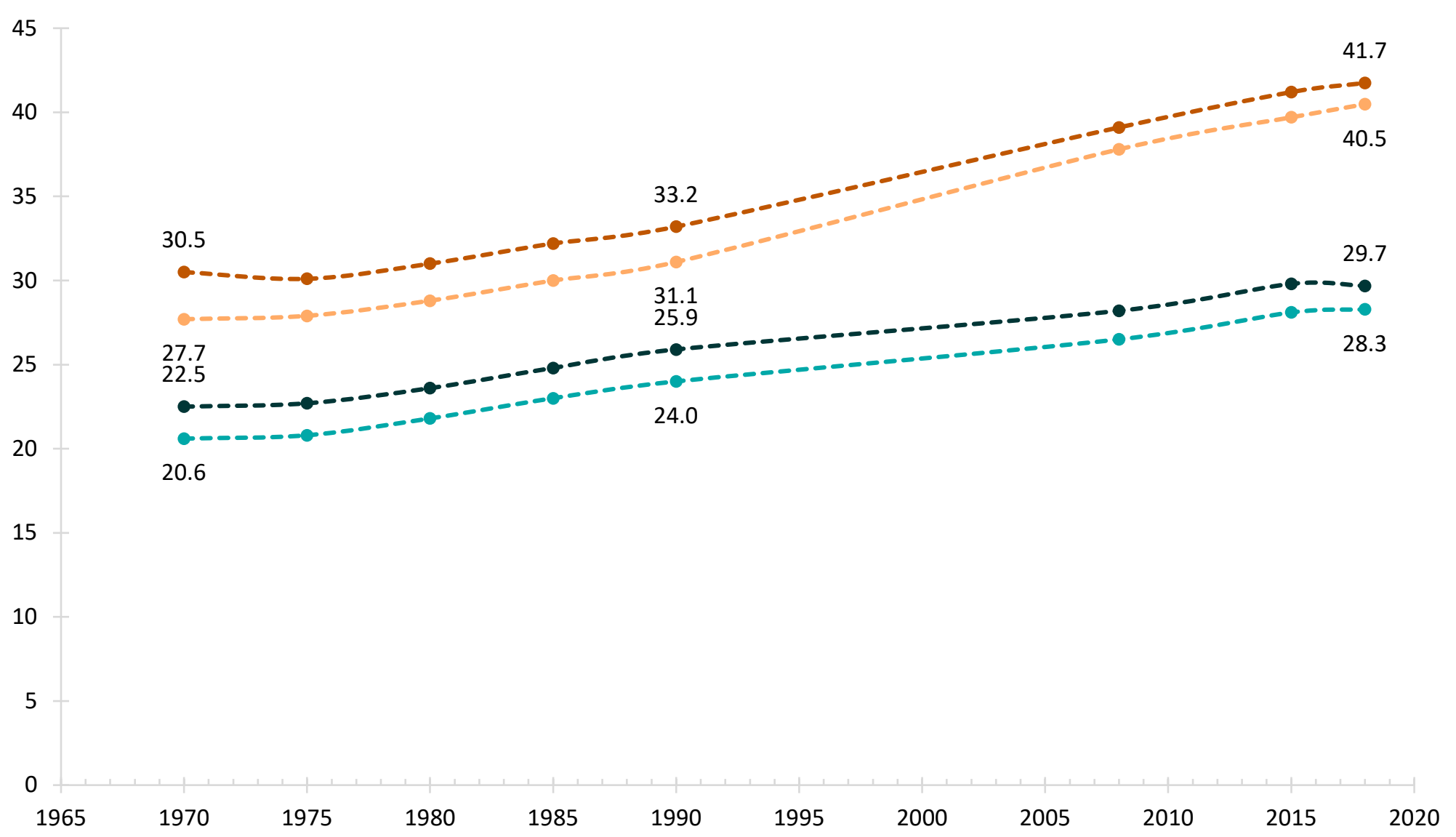

Source: NCFMR analyses of 1970-1990 National Center for Health Statistics; ACS 2008-2018 1-year estimates 


$$
\begin{aligned}
& \text { B } \\
& \text { Bo } \\
& \text { The } \\
& \text { She } \\
& \text { as }
\end{aligned}
$$

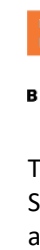

Figure 2. Median Age at First Divorce by Race/Ethnicity, 2018

White Black Asian Hispanic Other

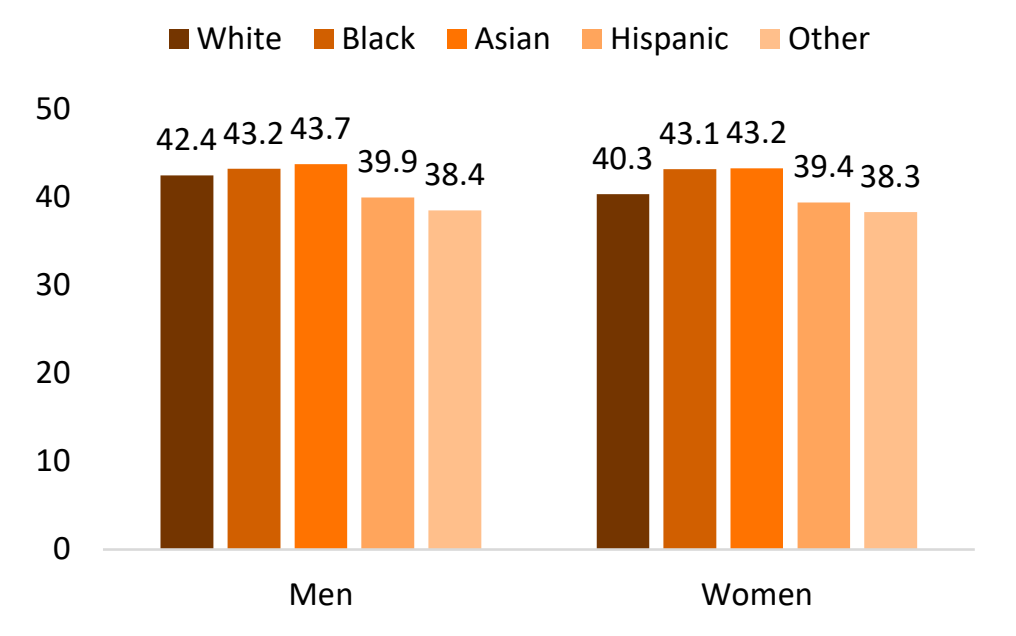

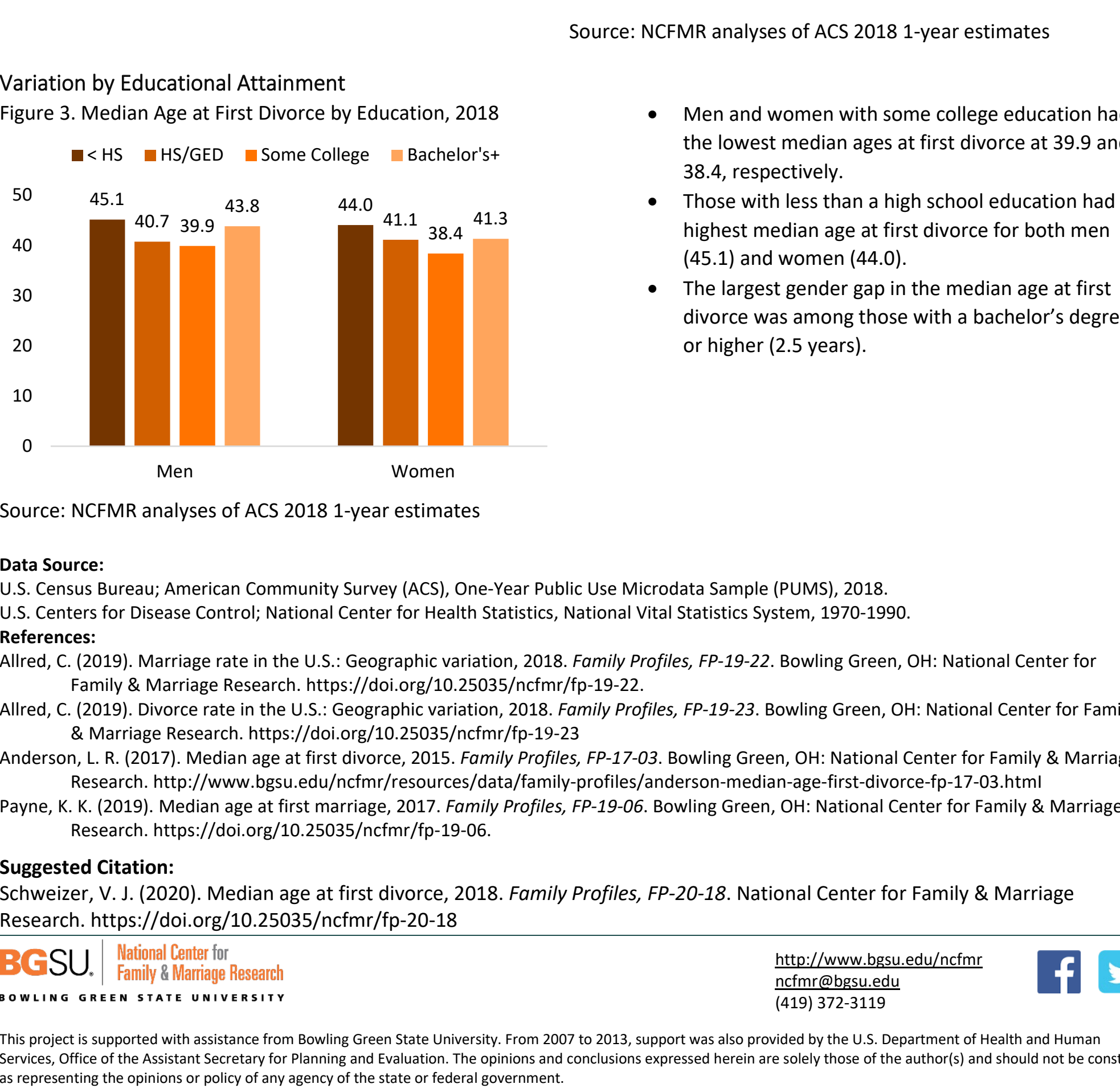

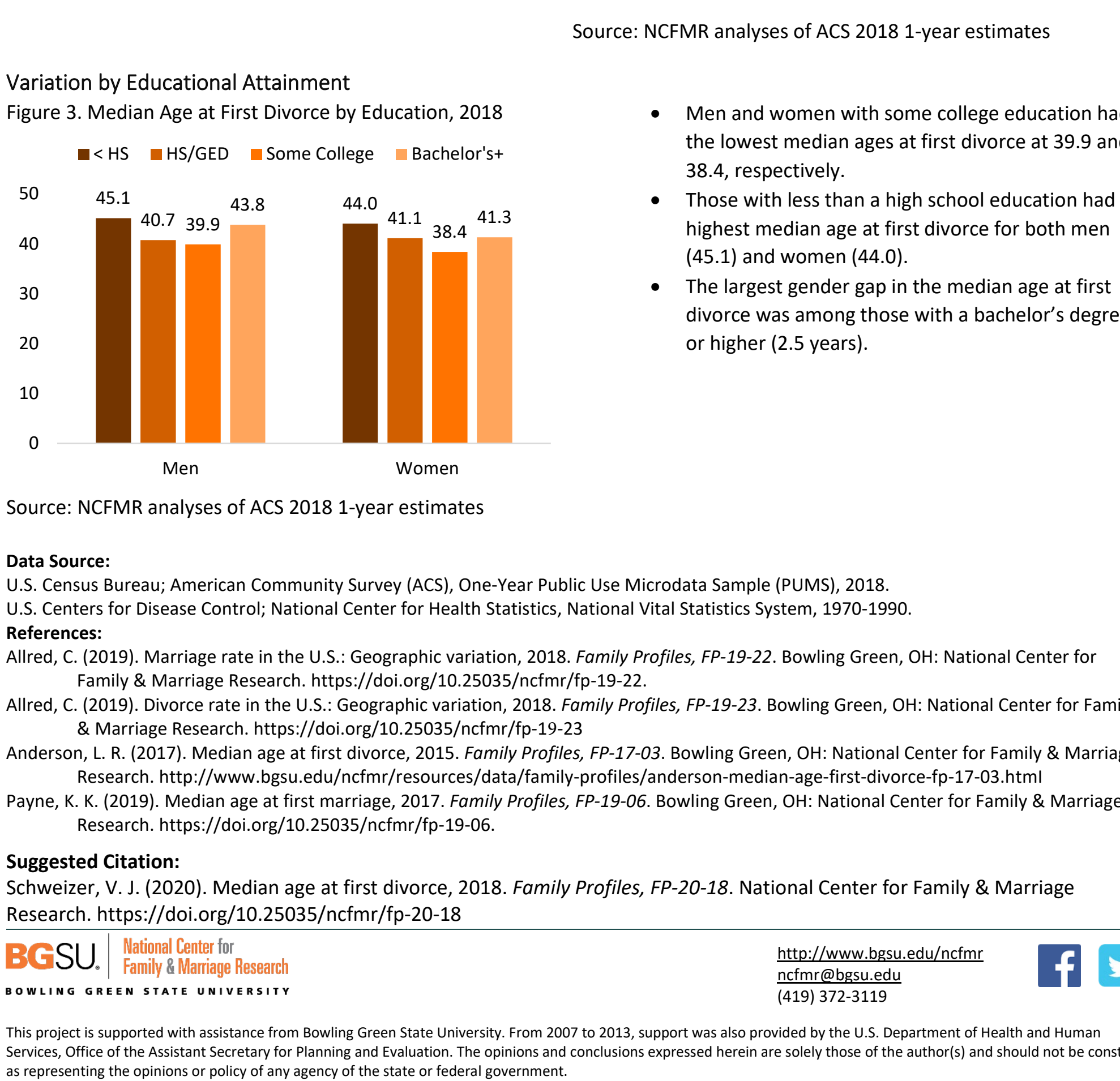

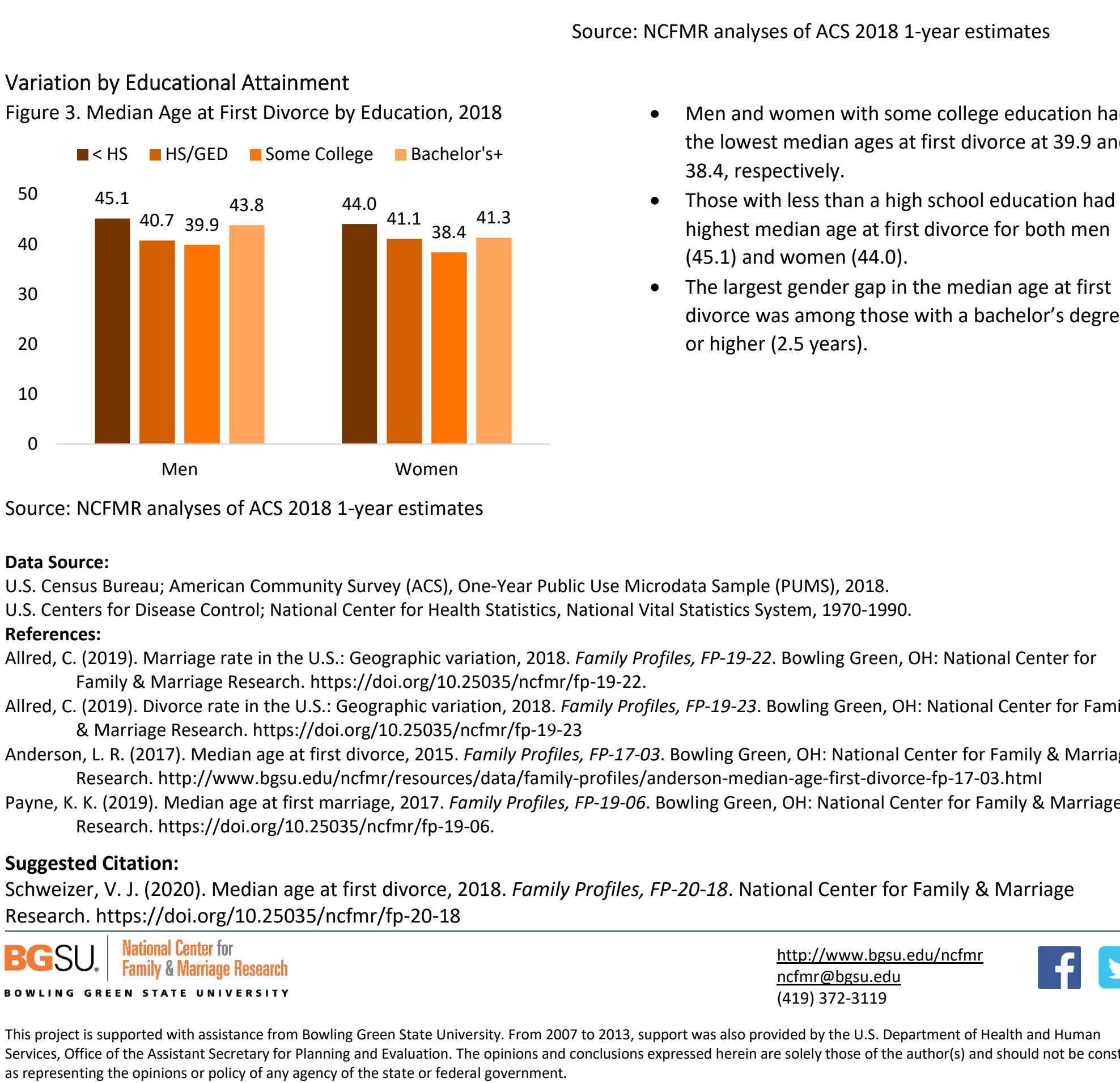

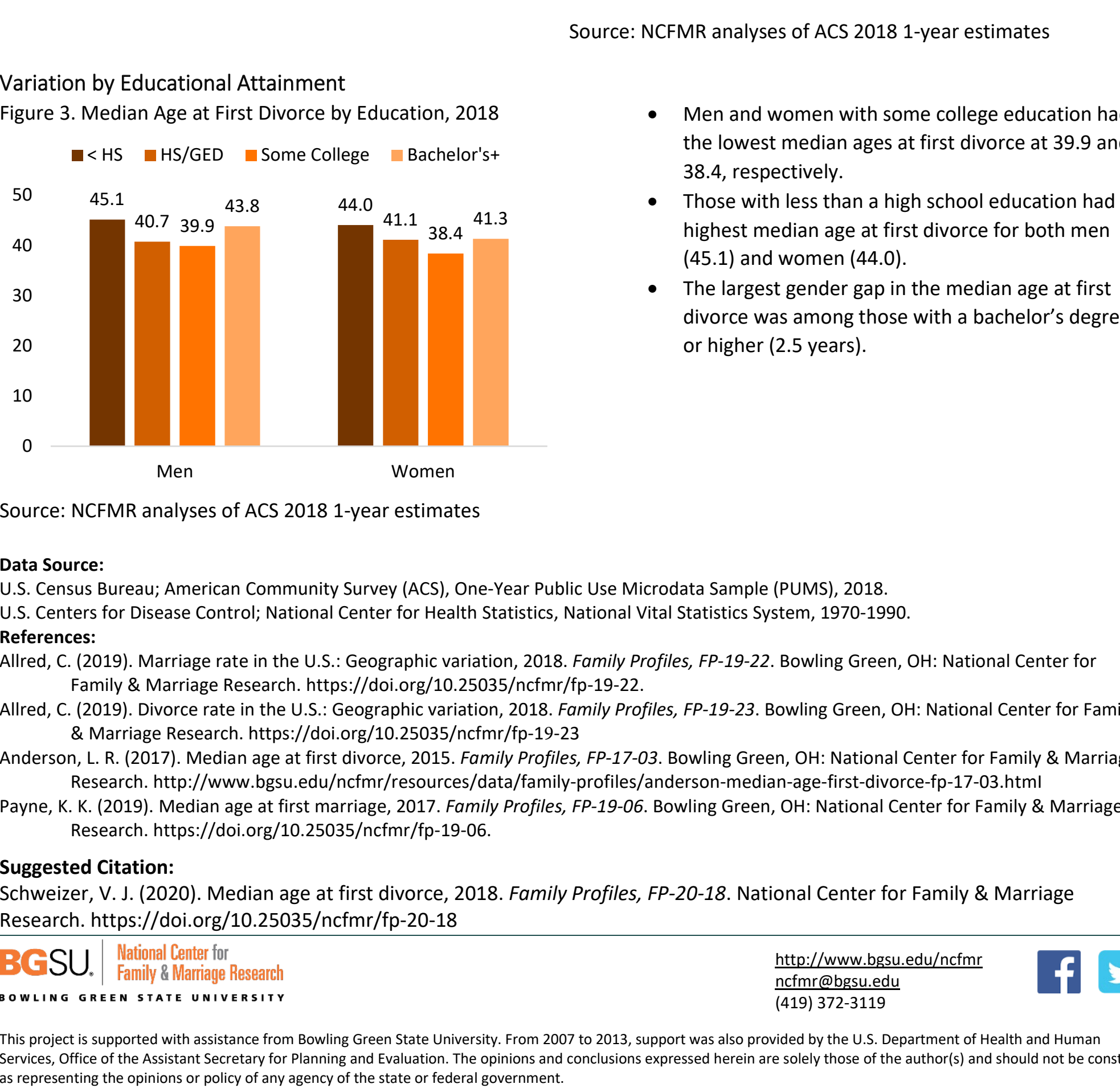

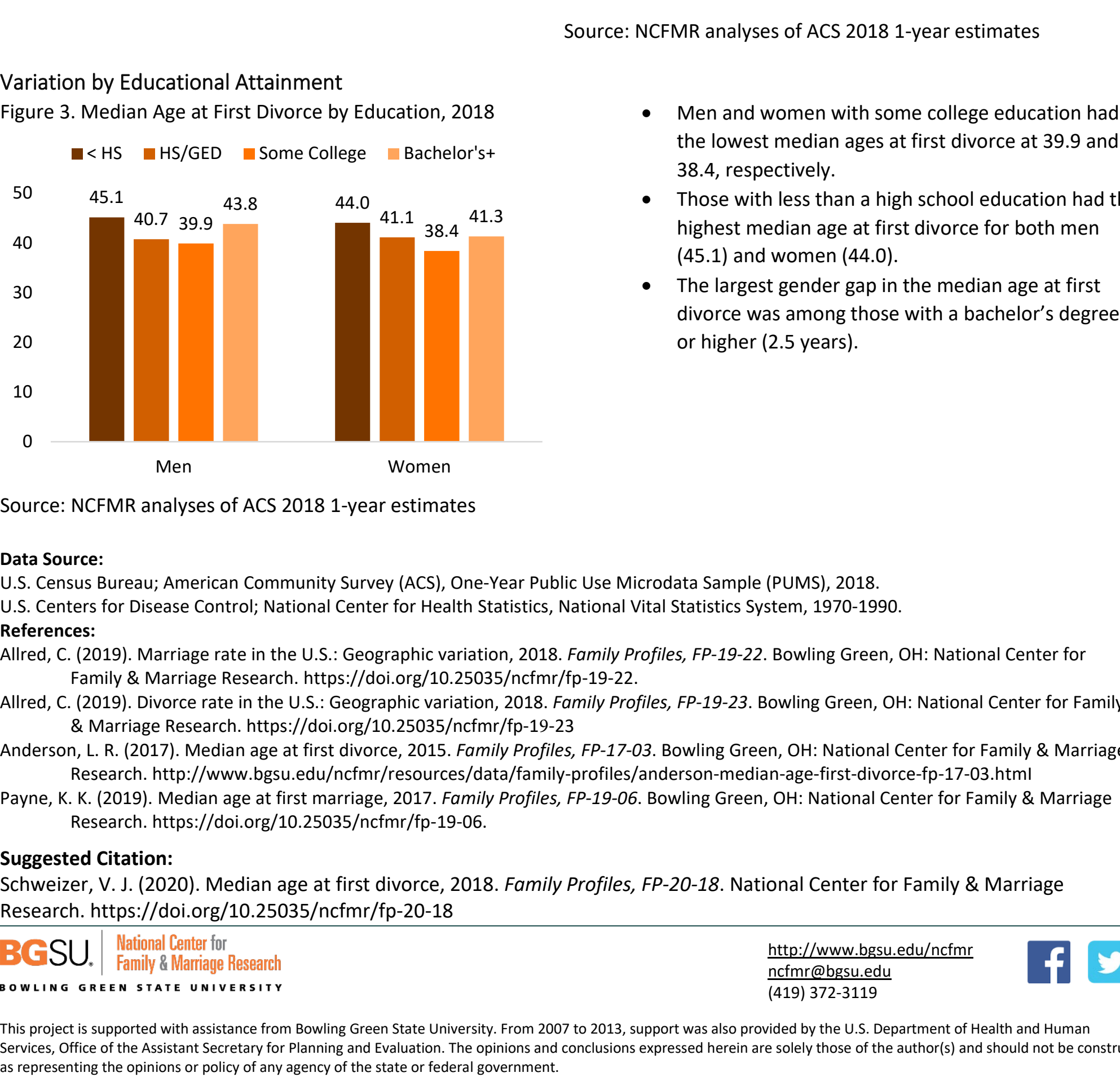

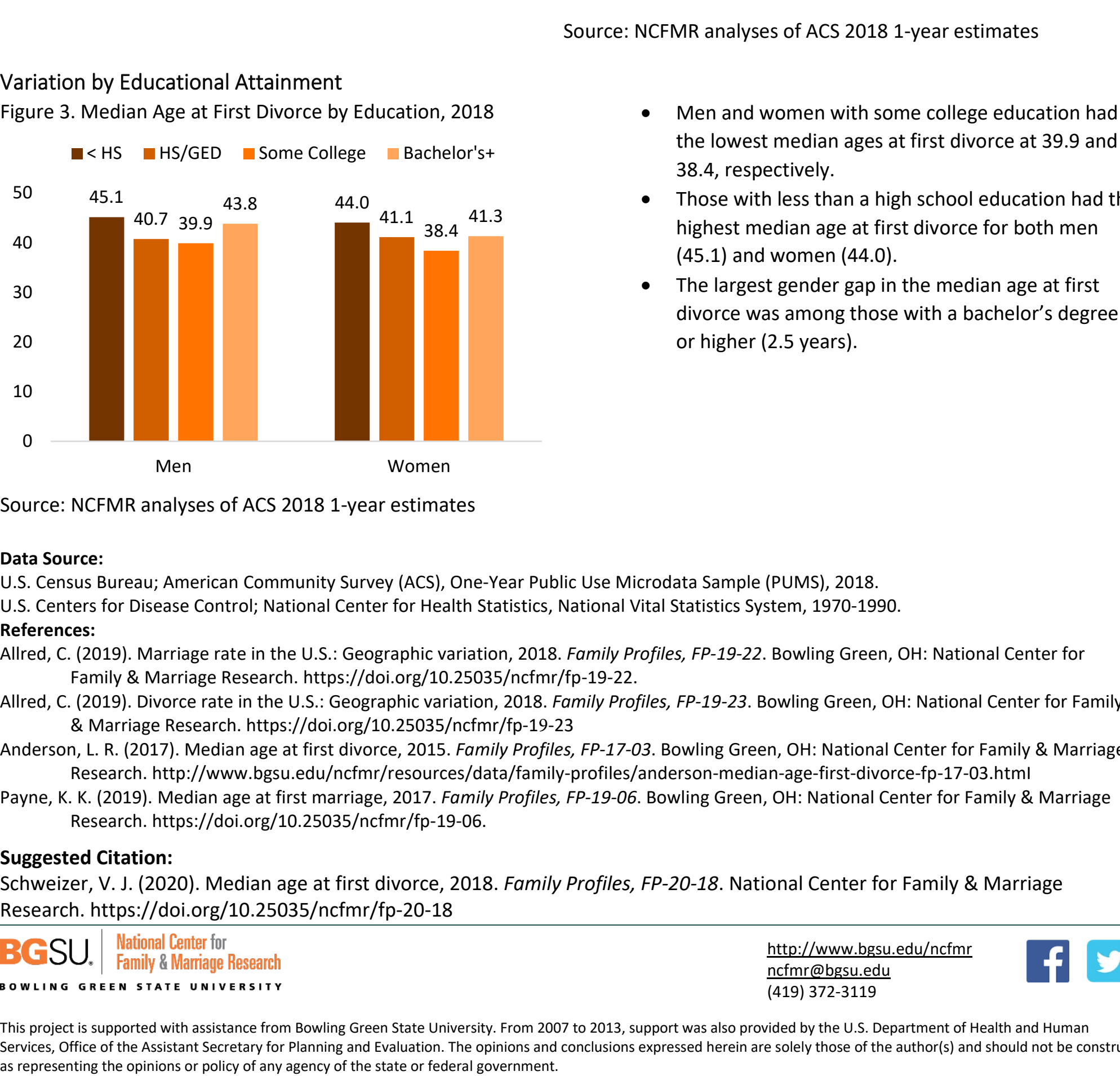

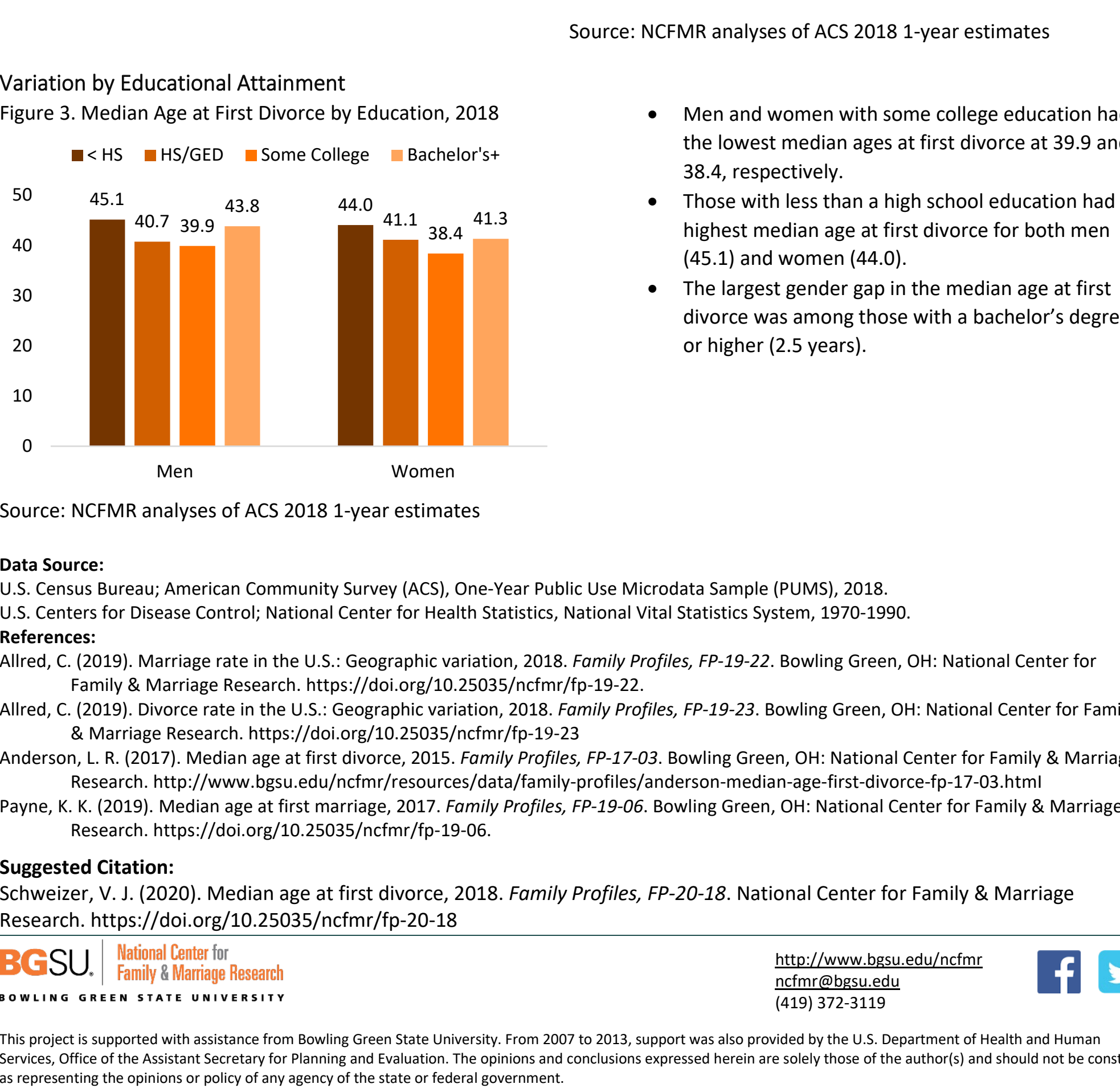

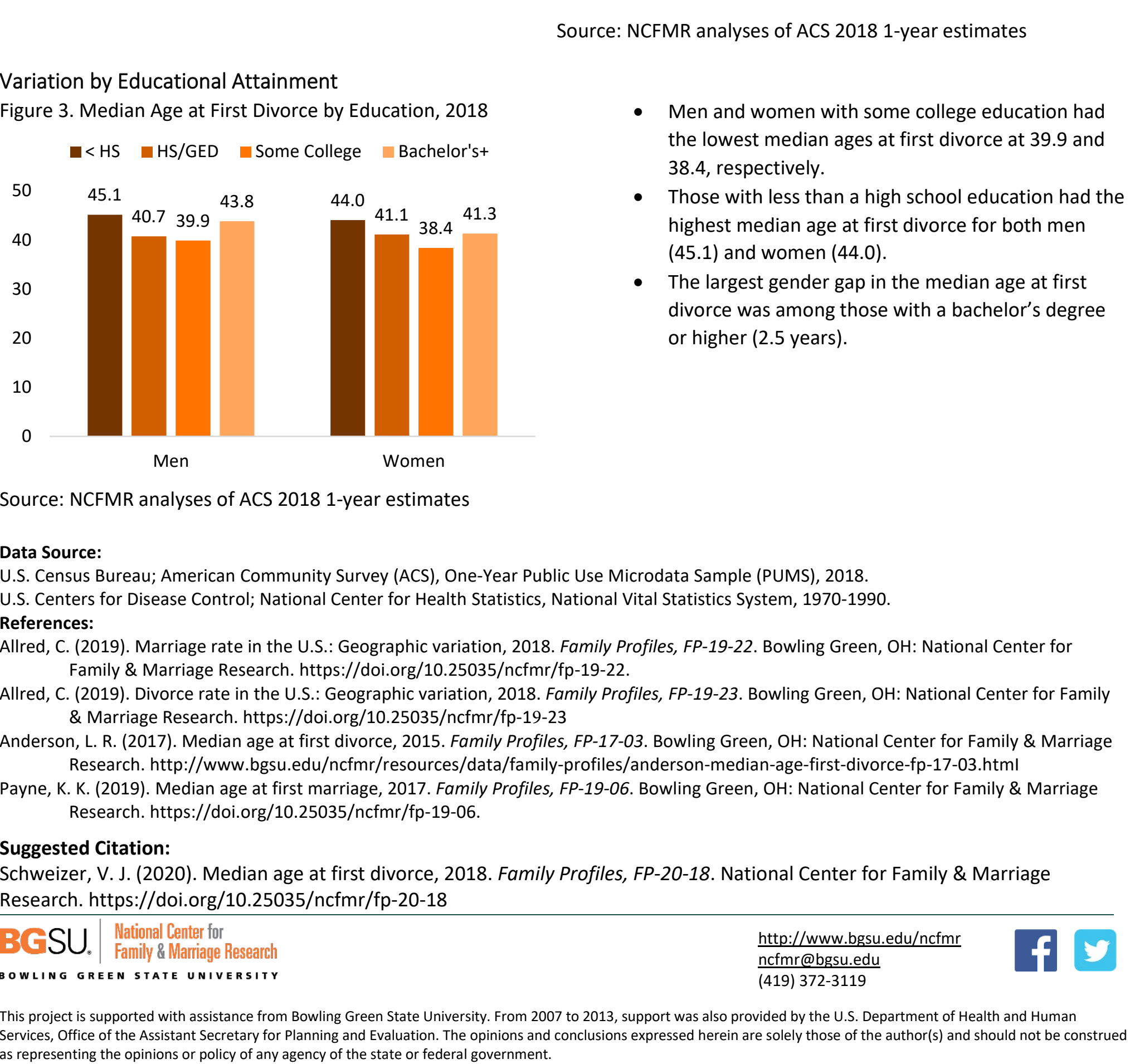

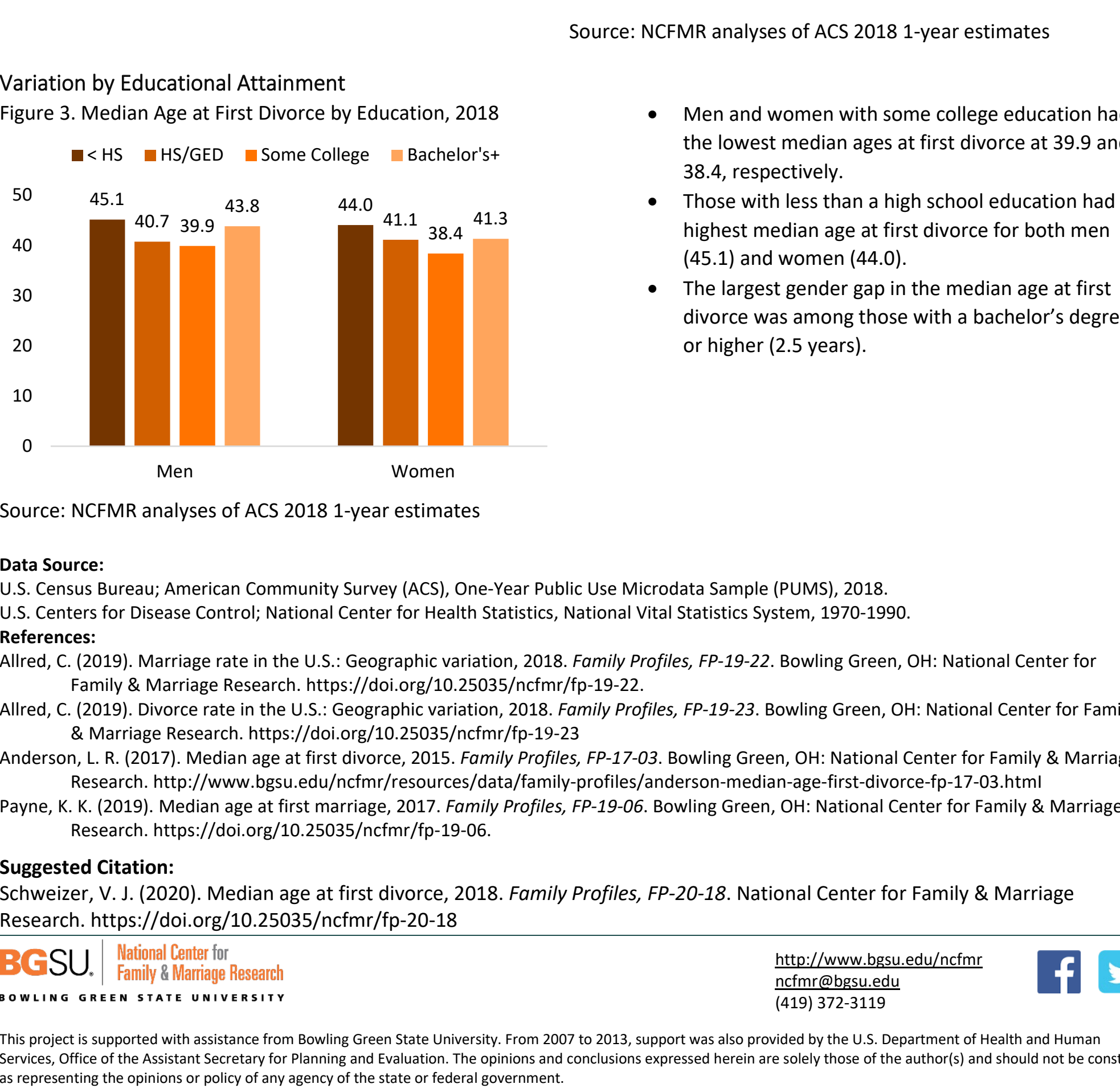

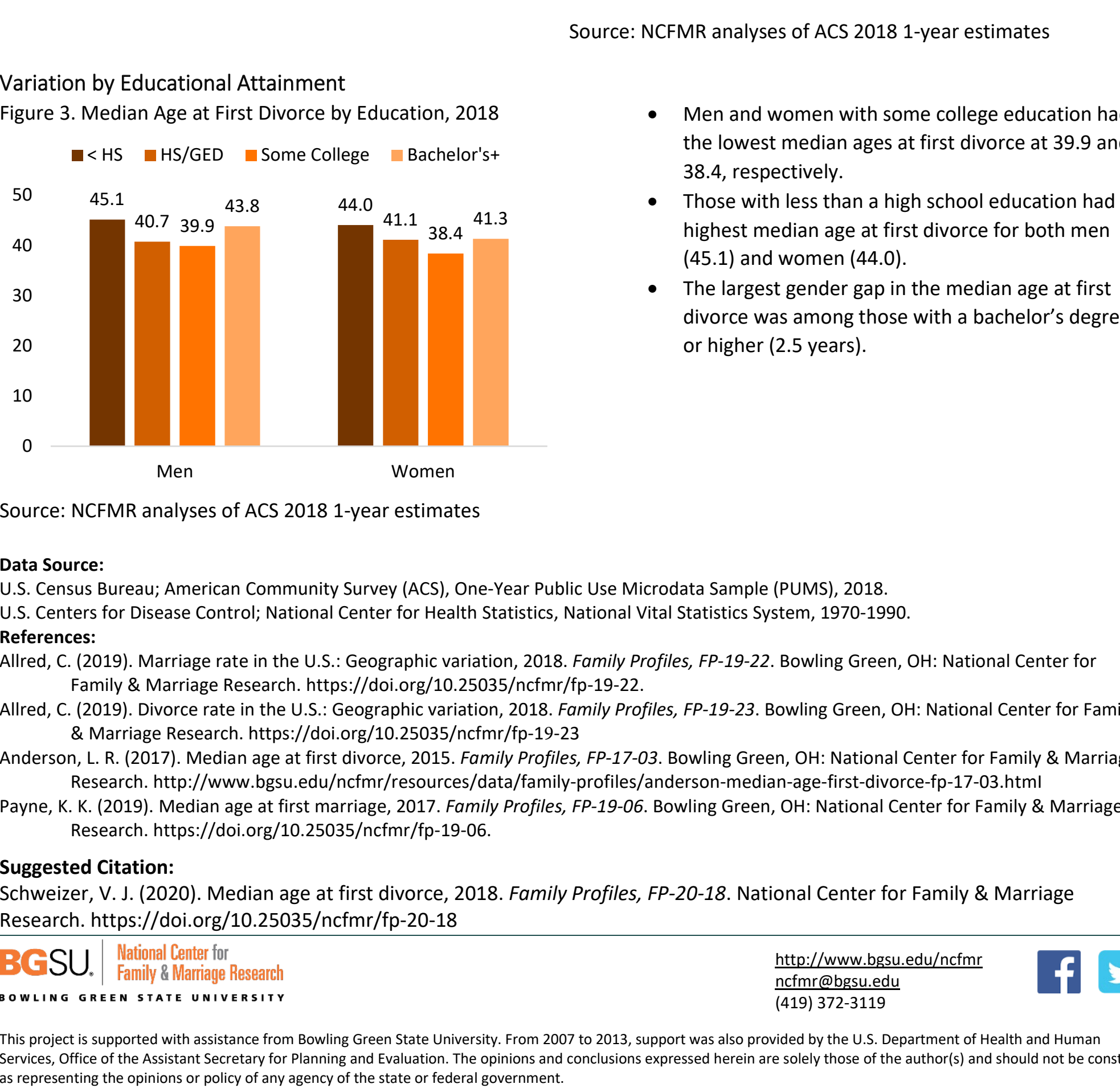

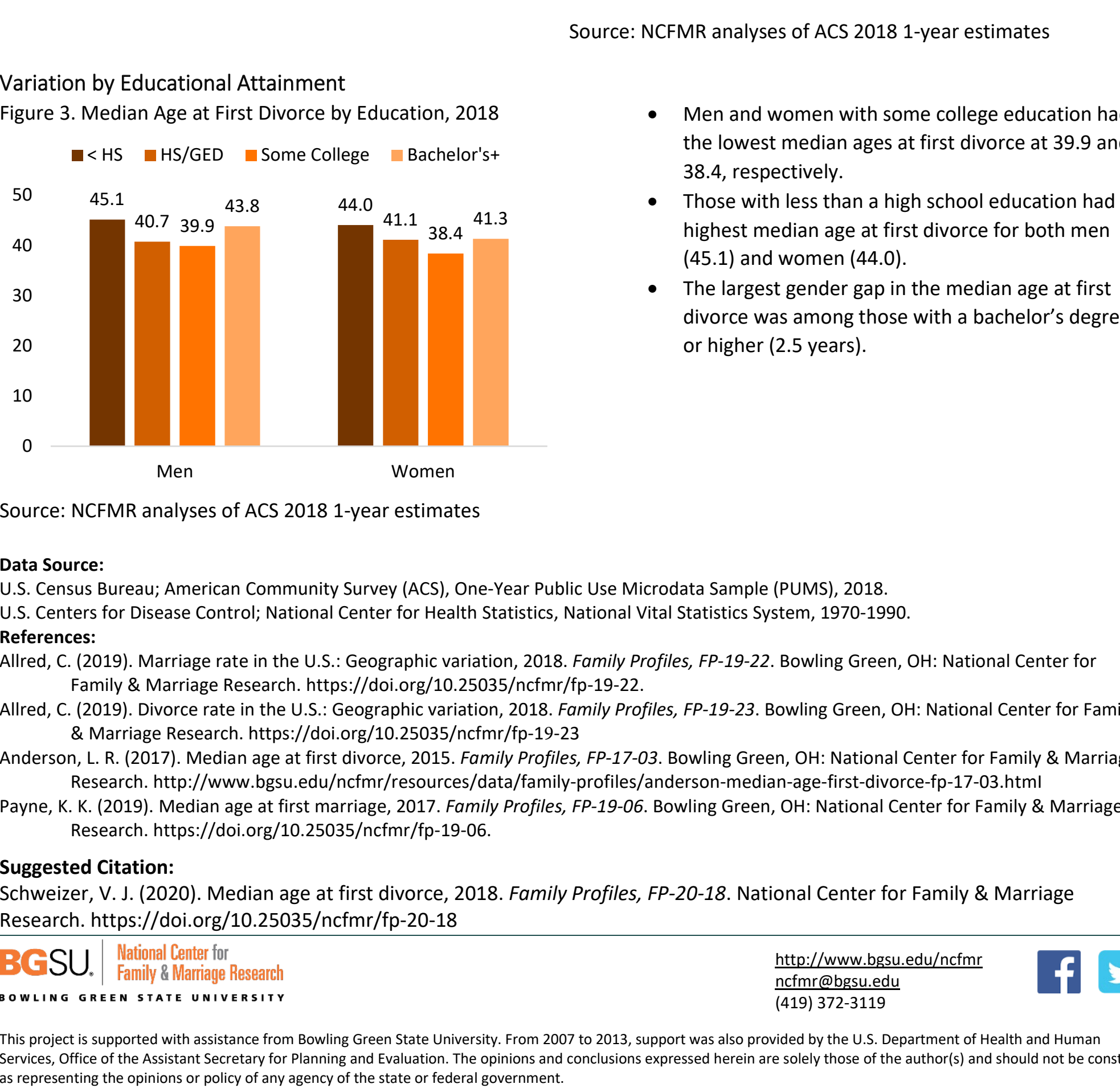

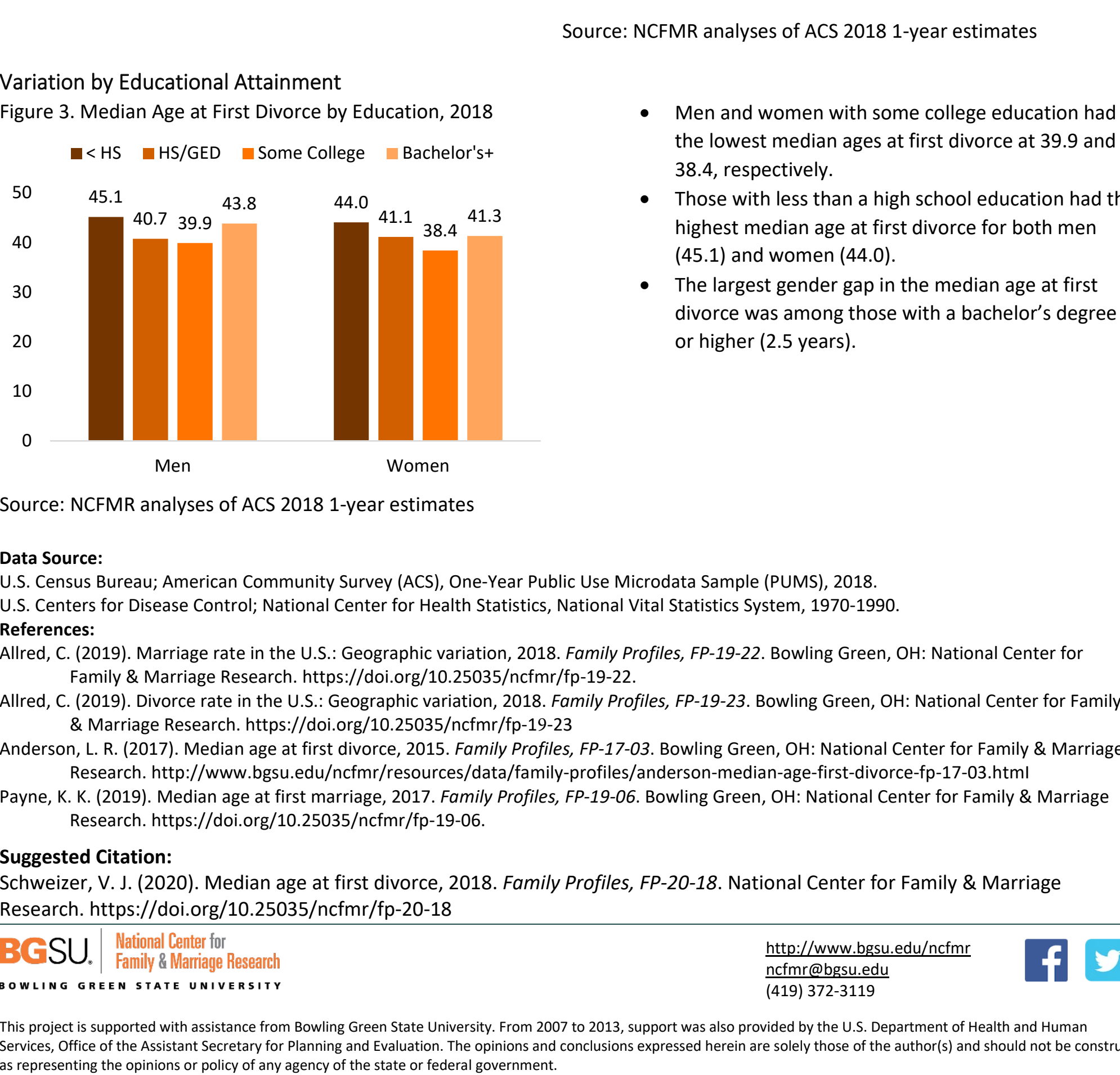

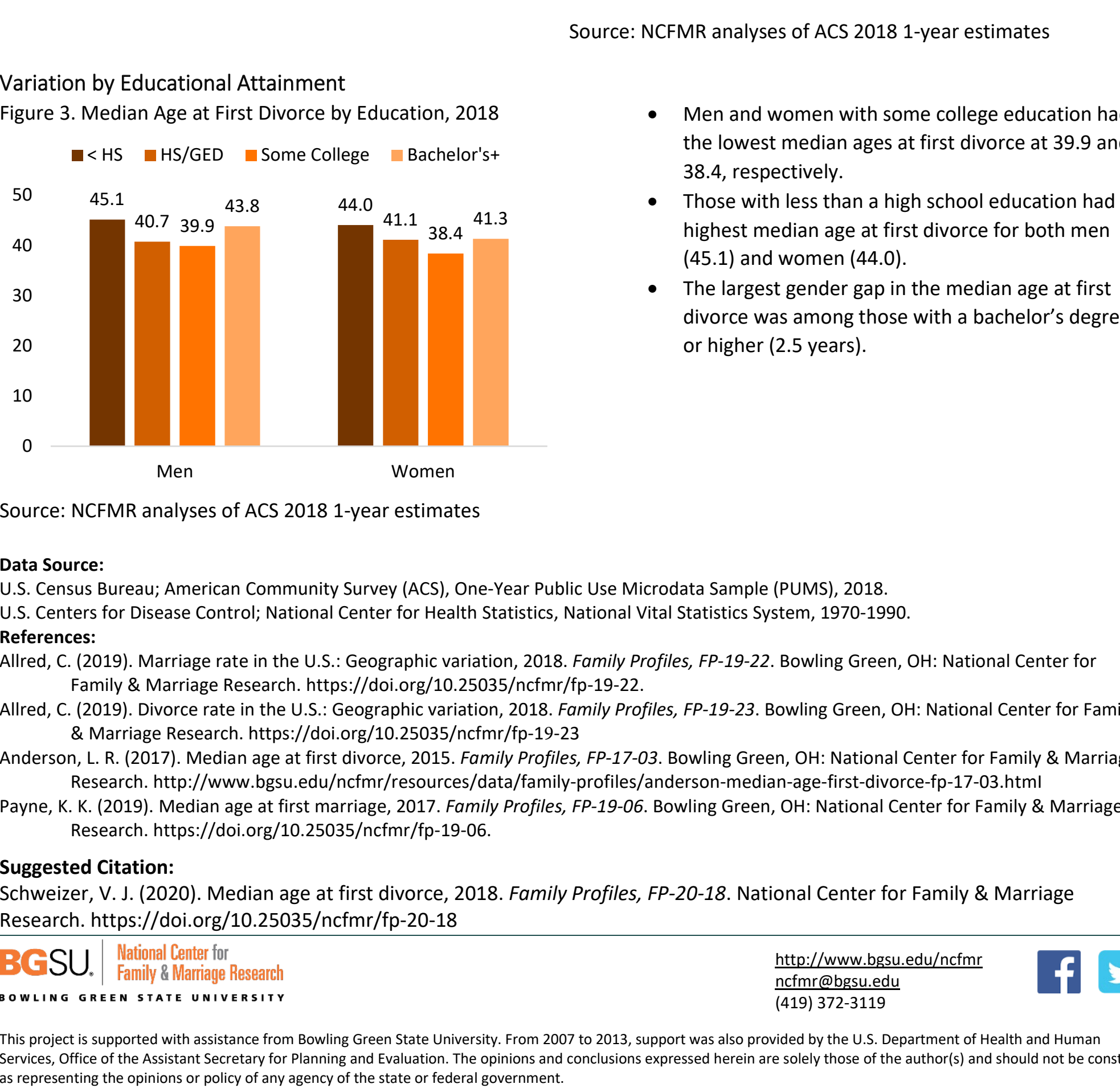

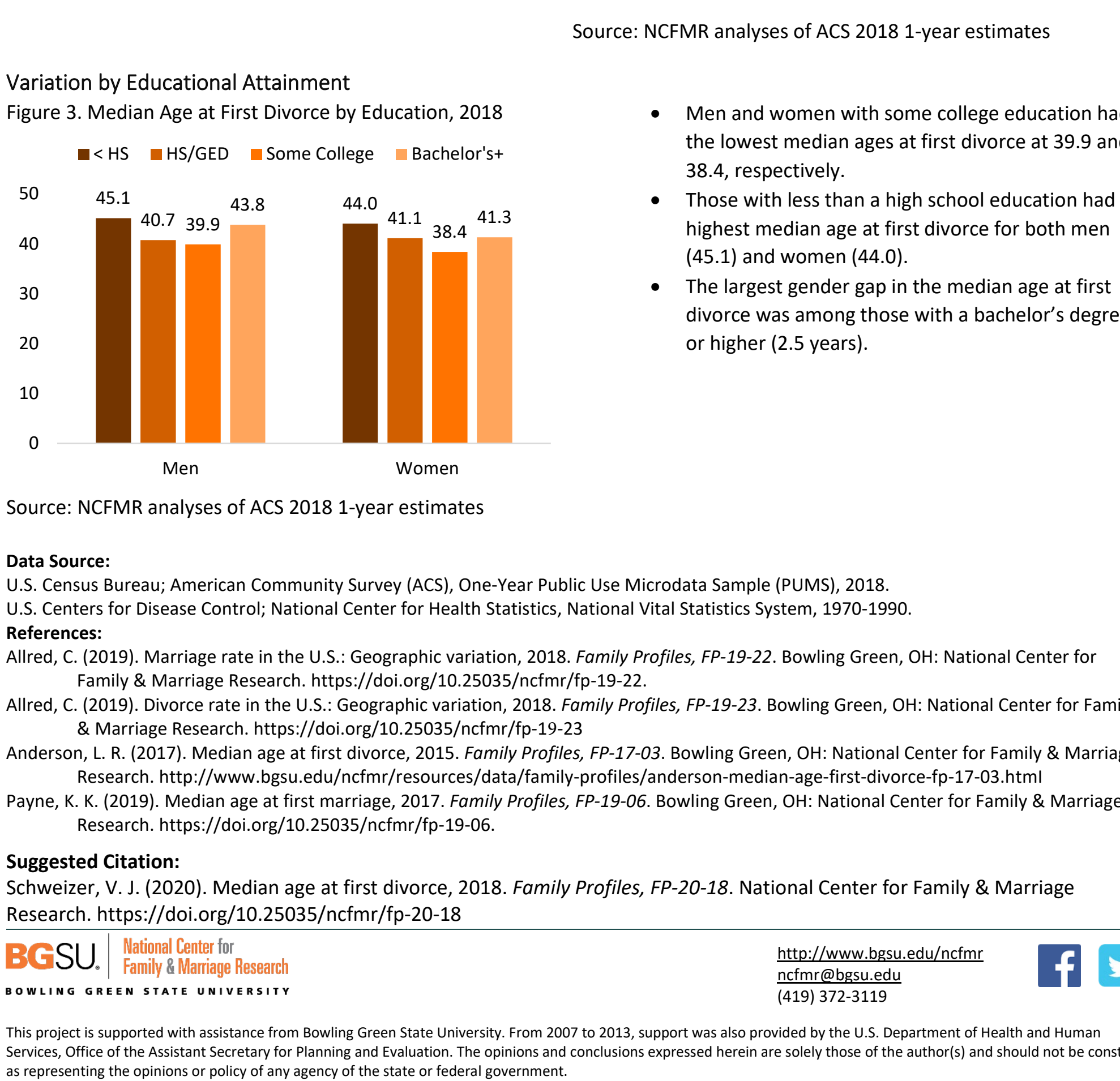

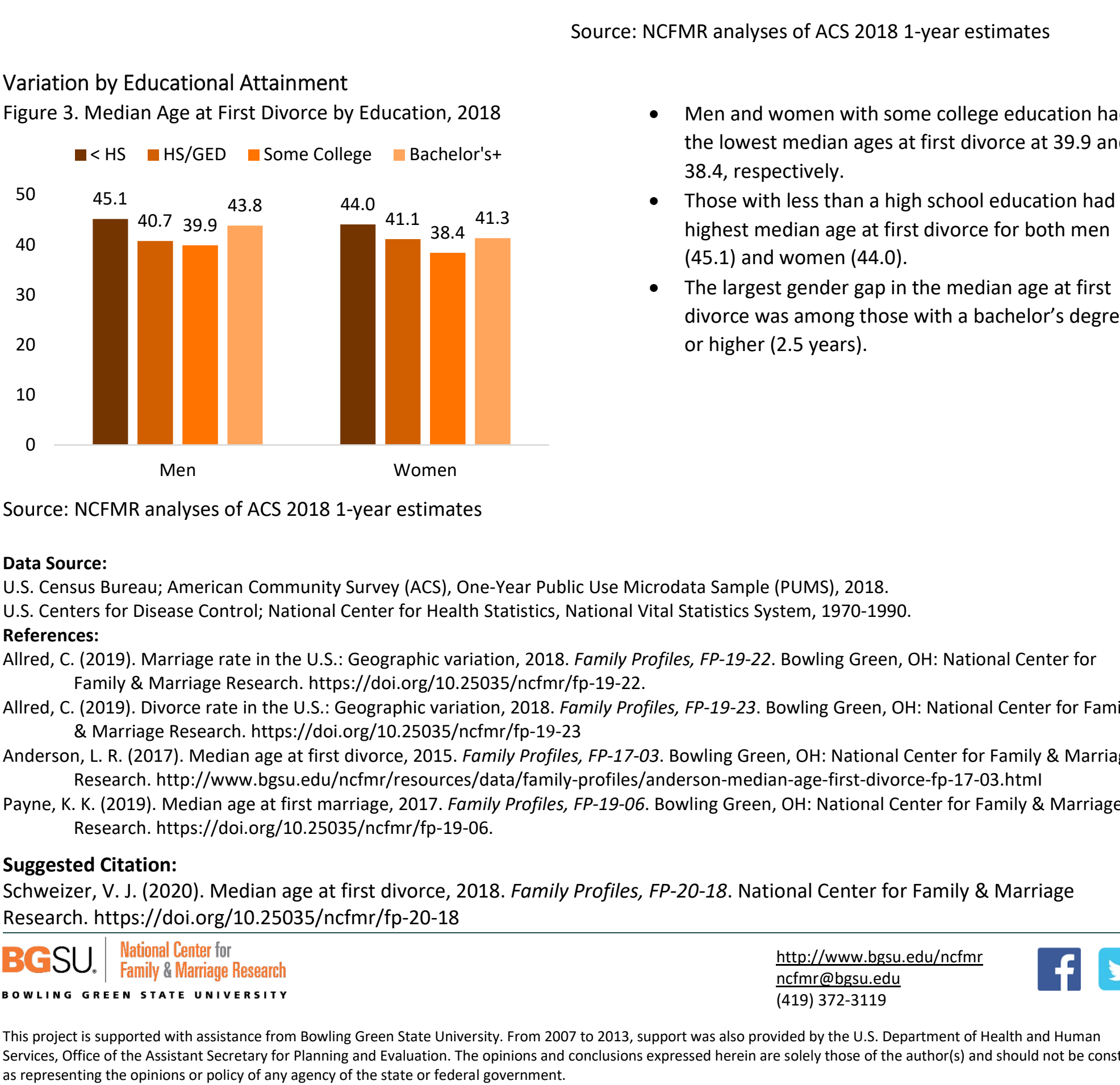

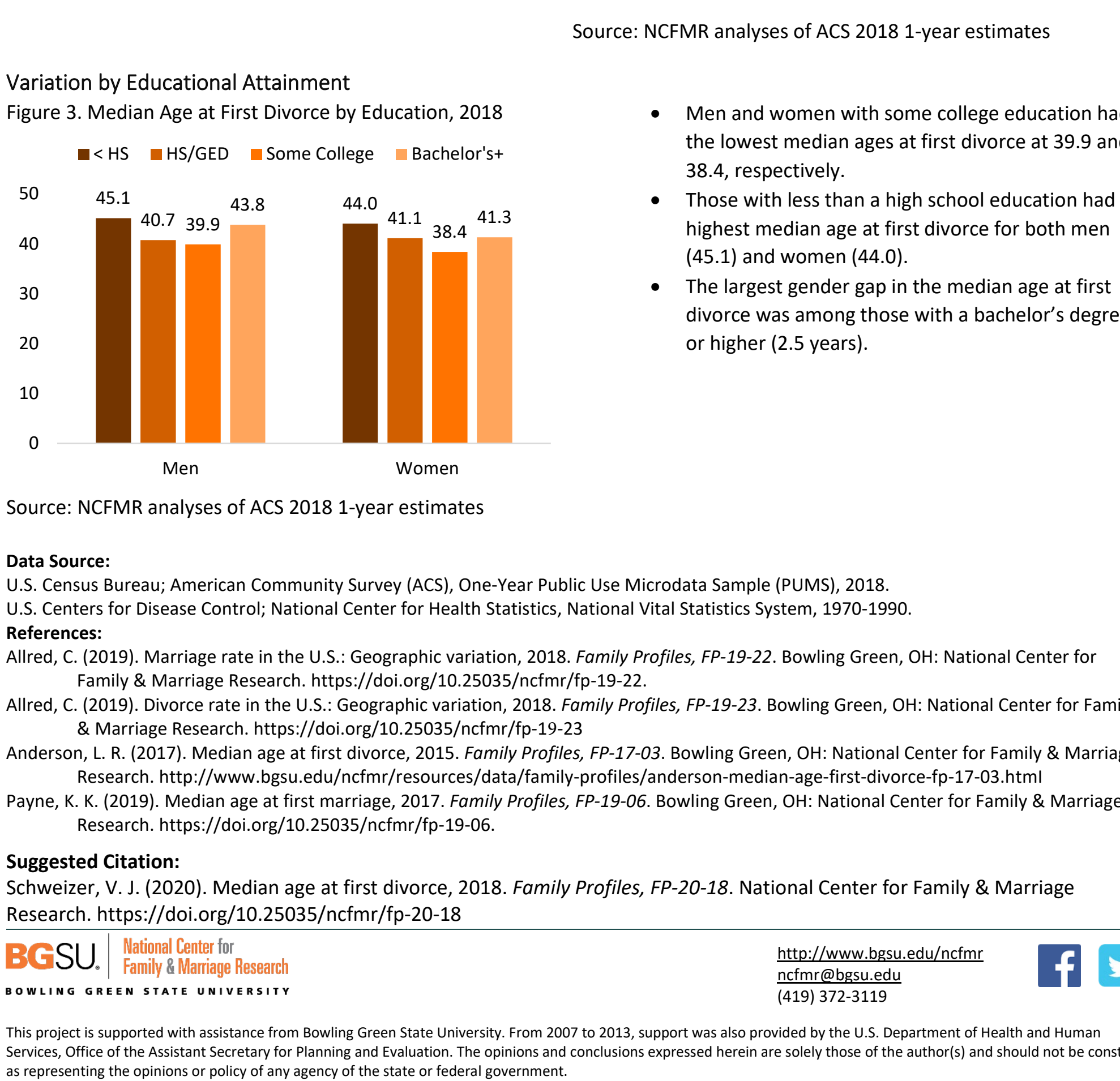

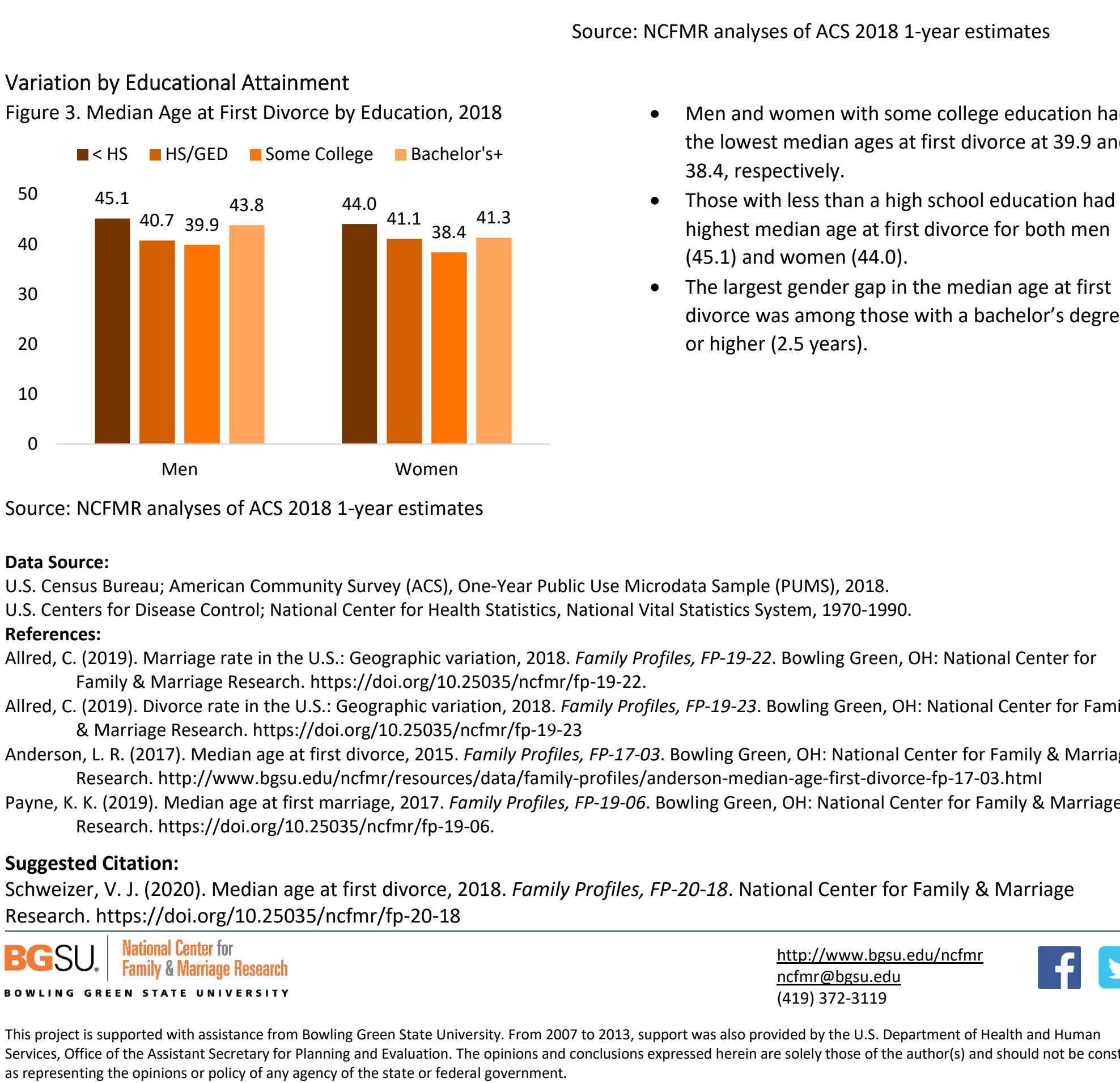

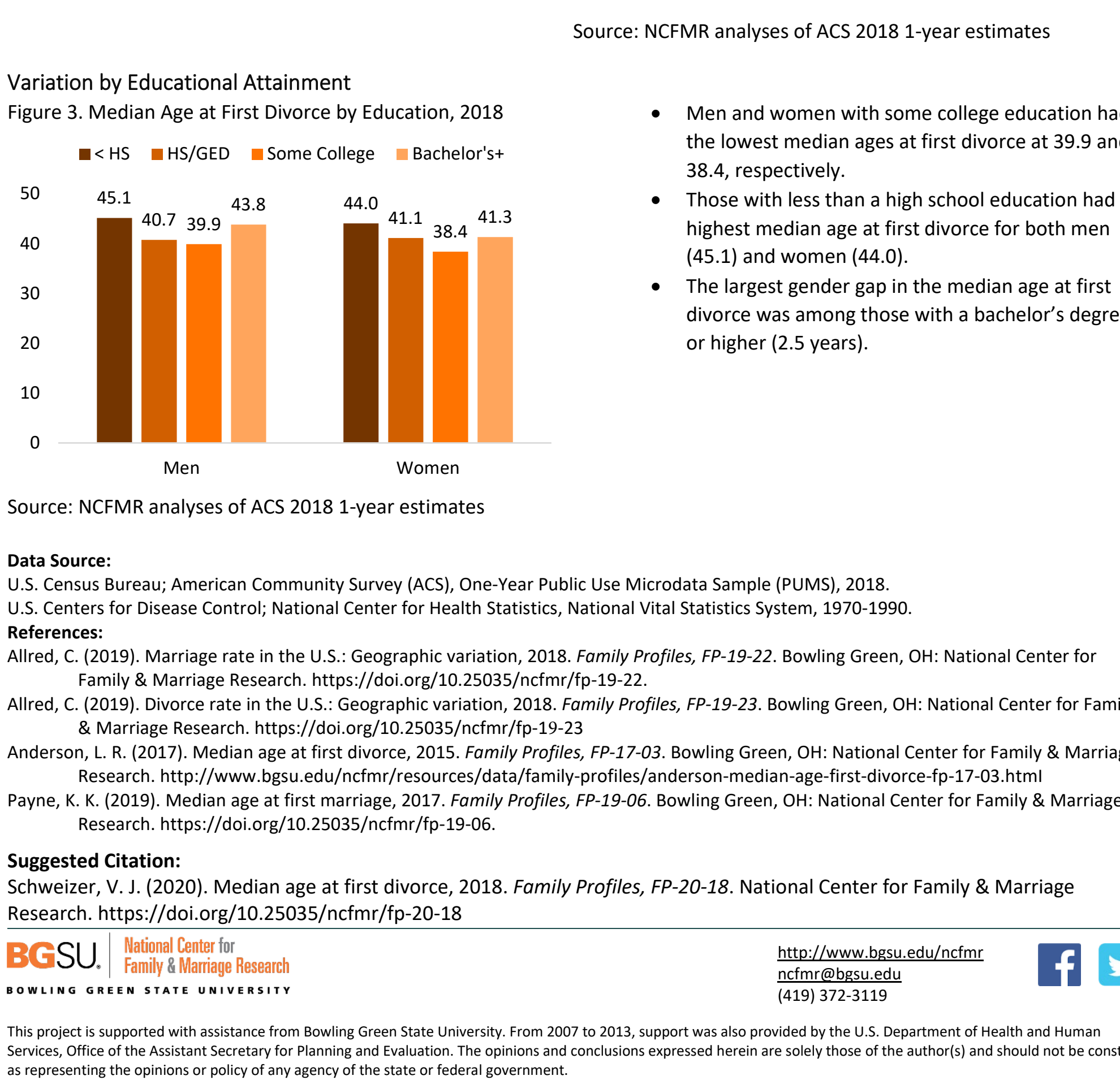

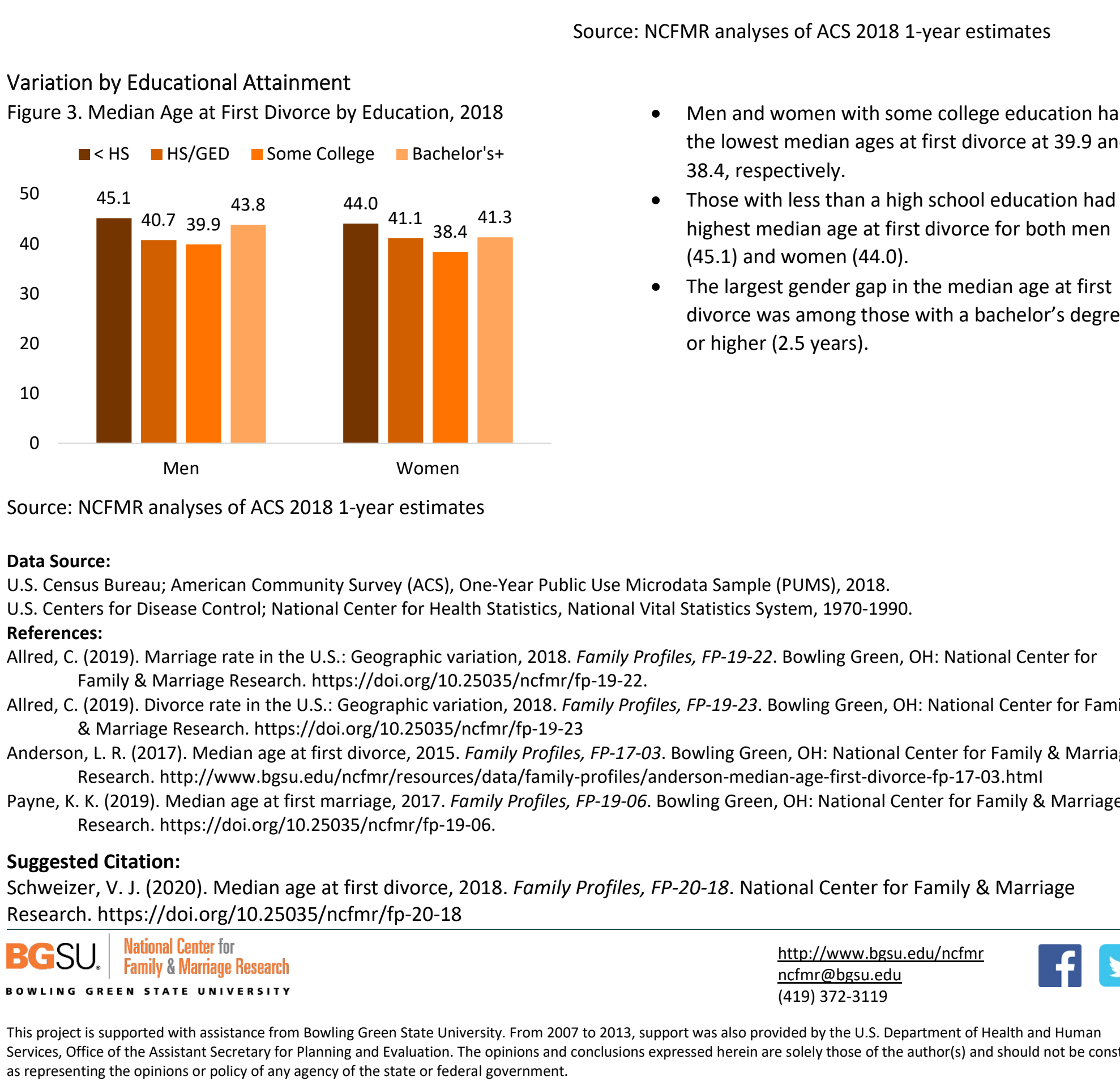

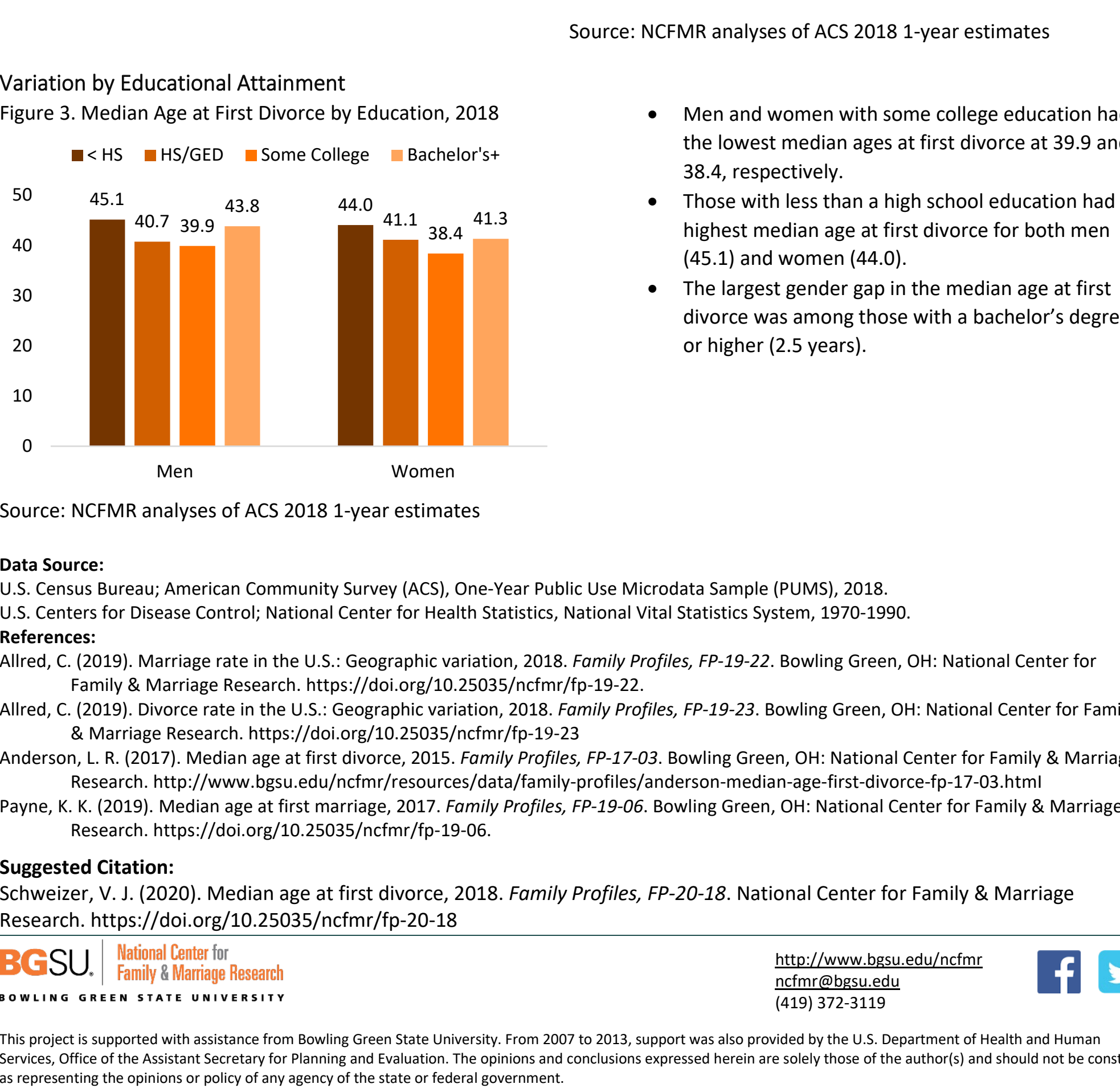

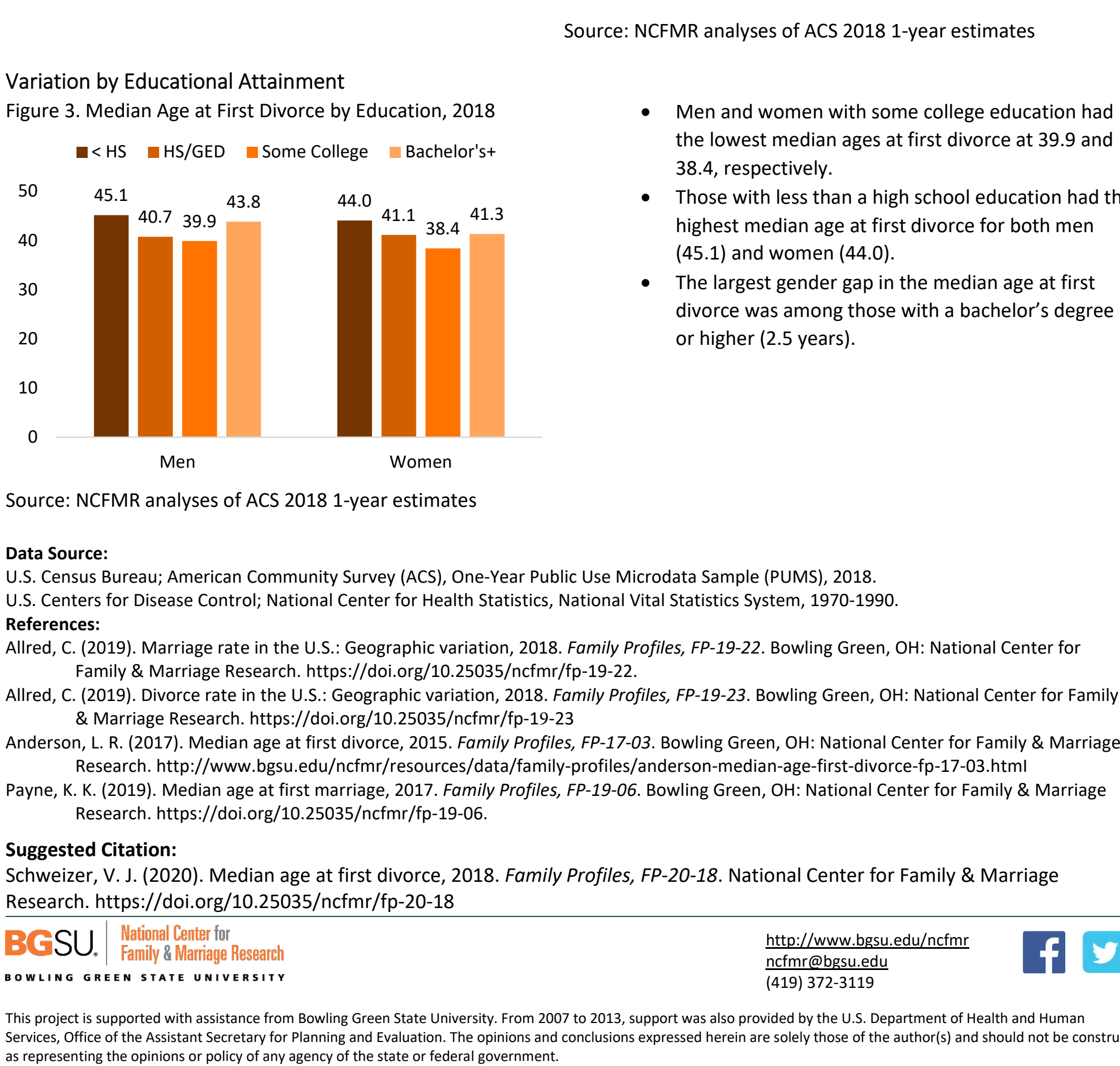

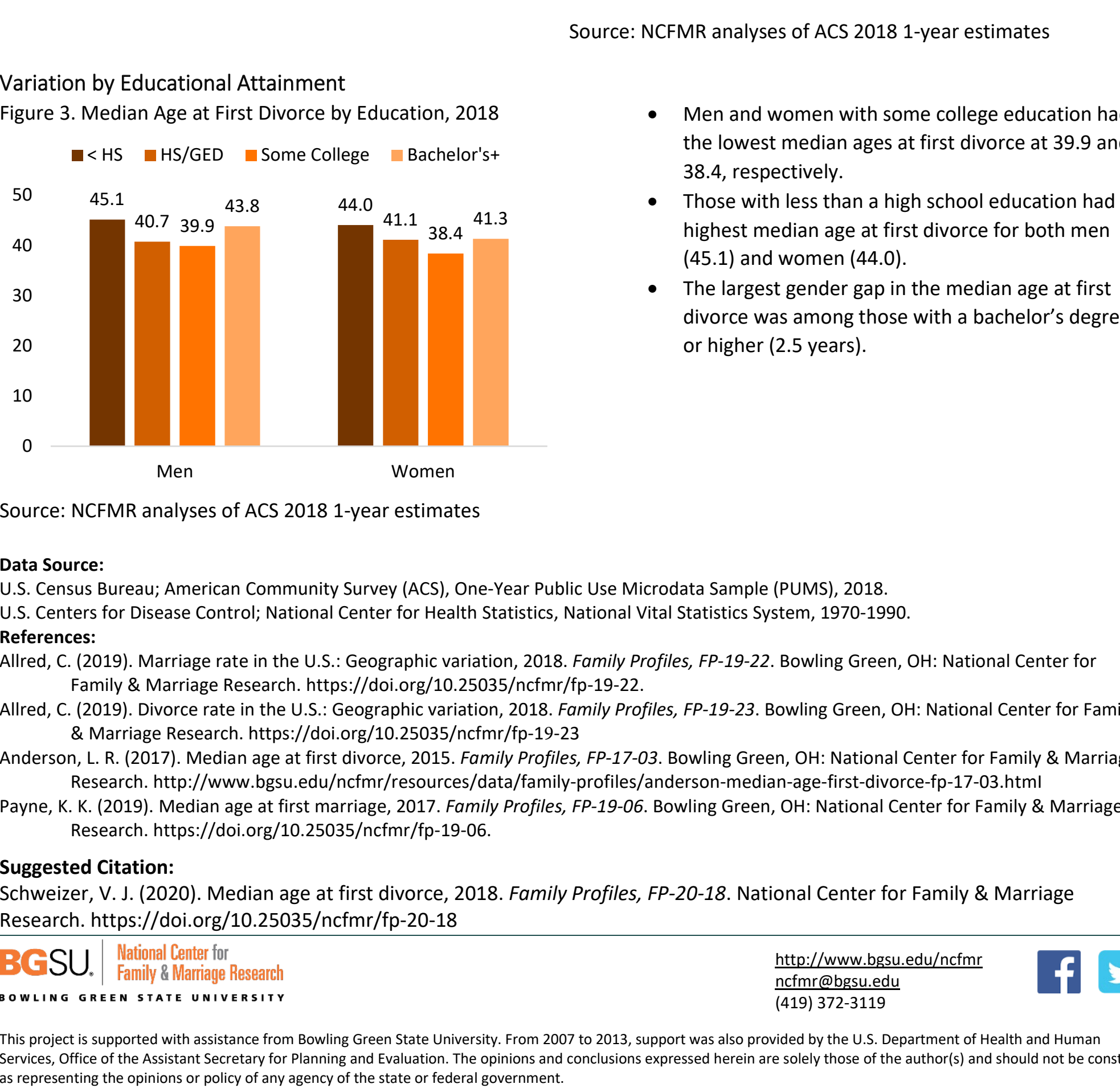

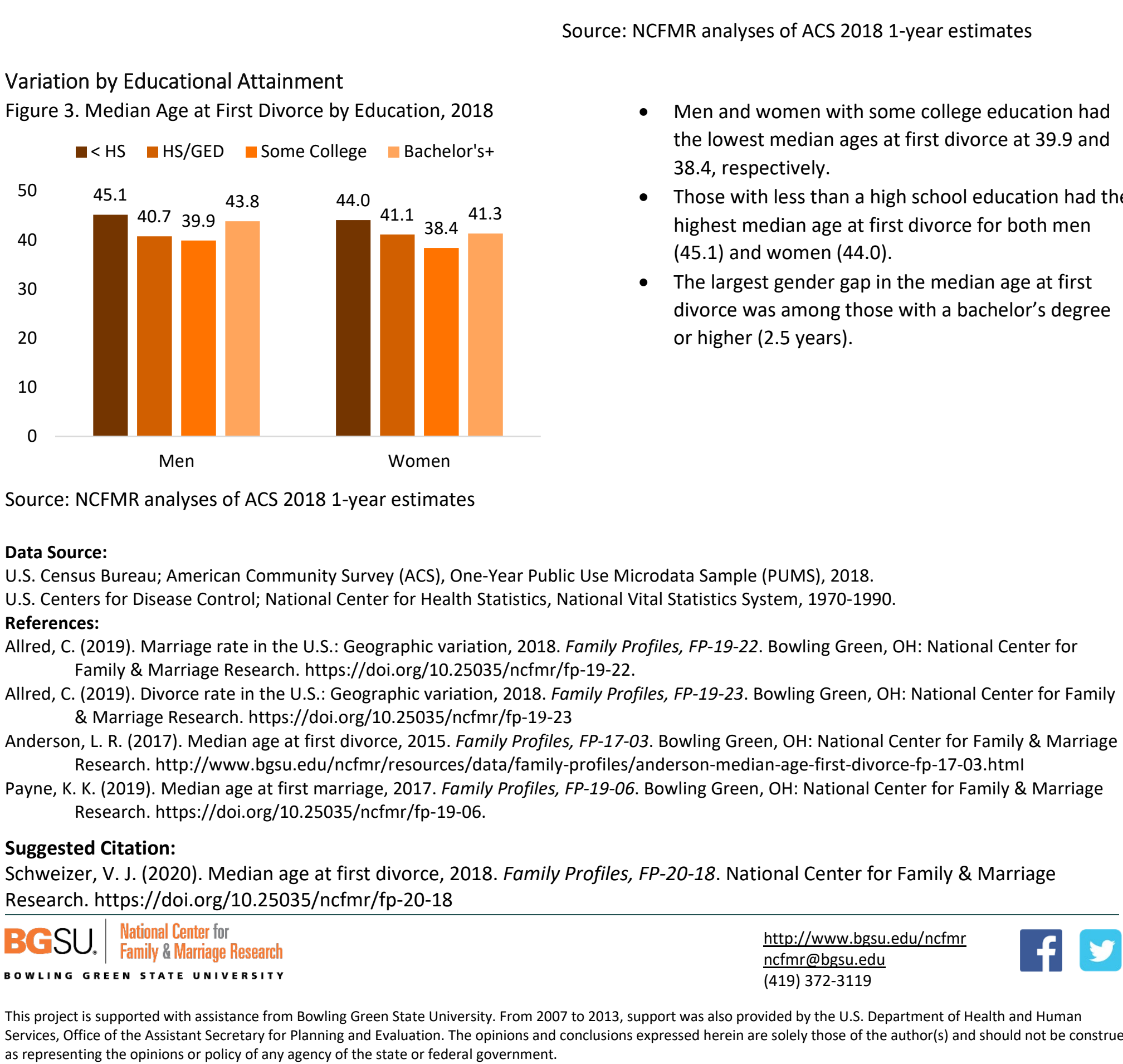

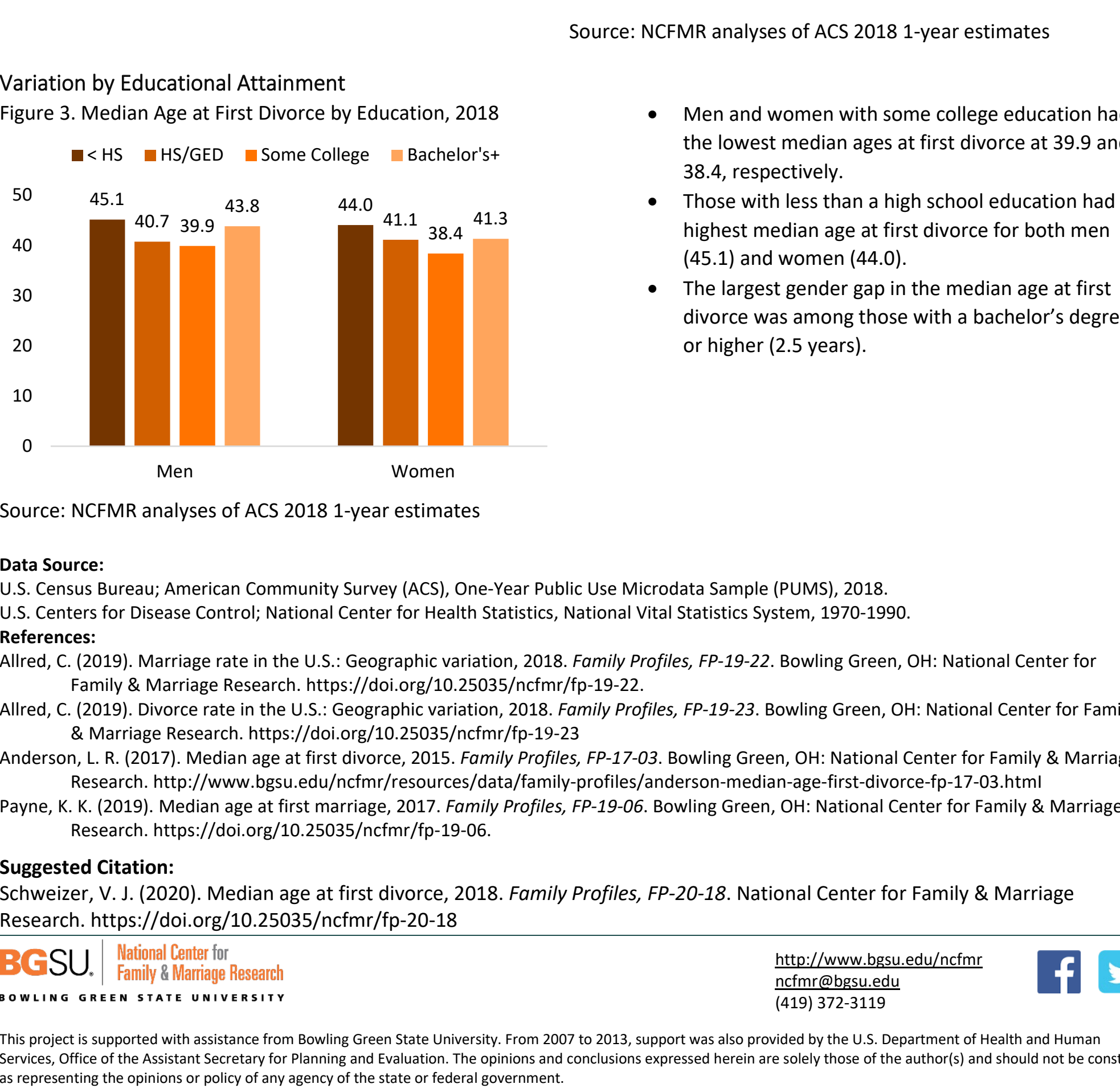

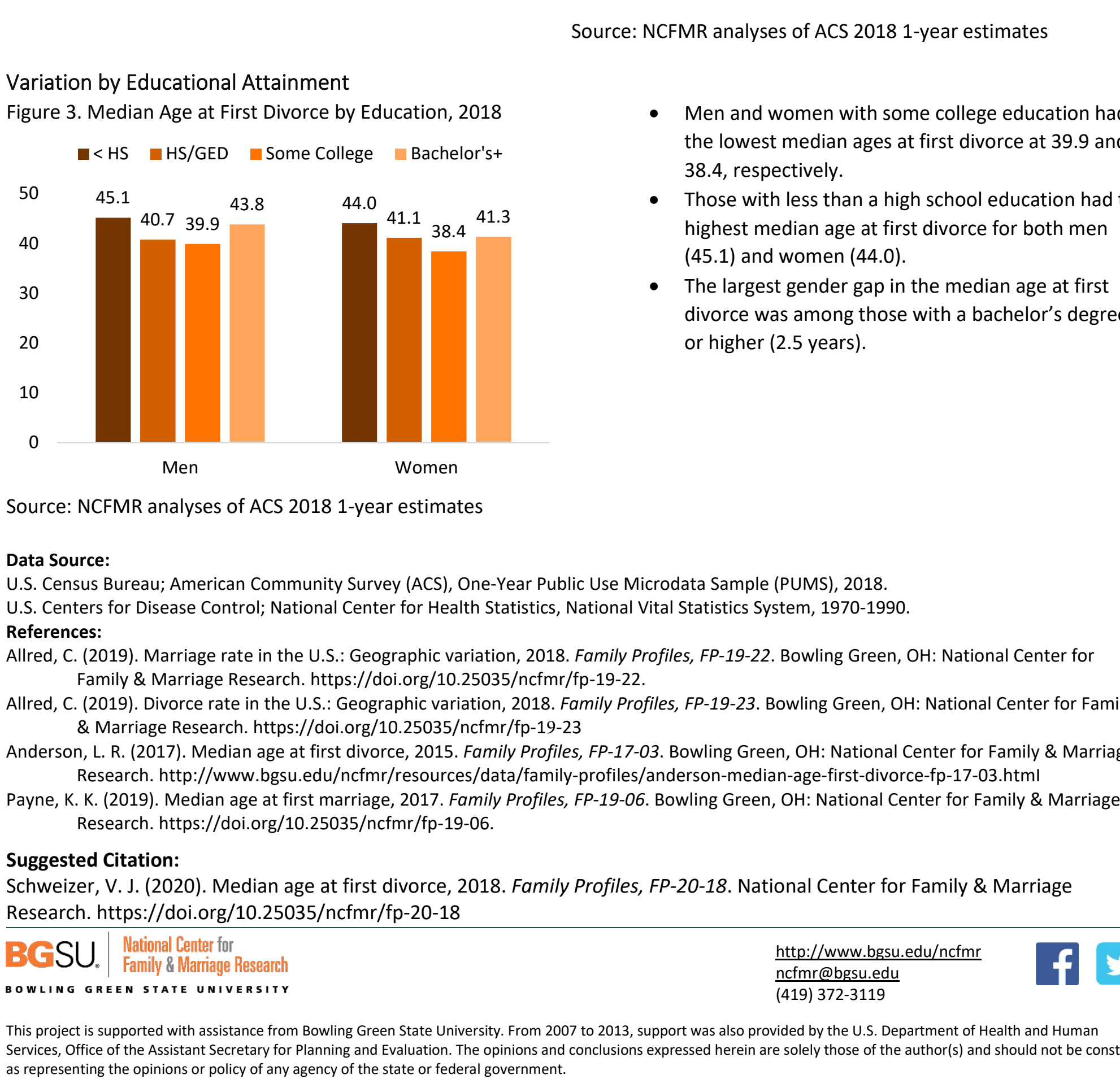

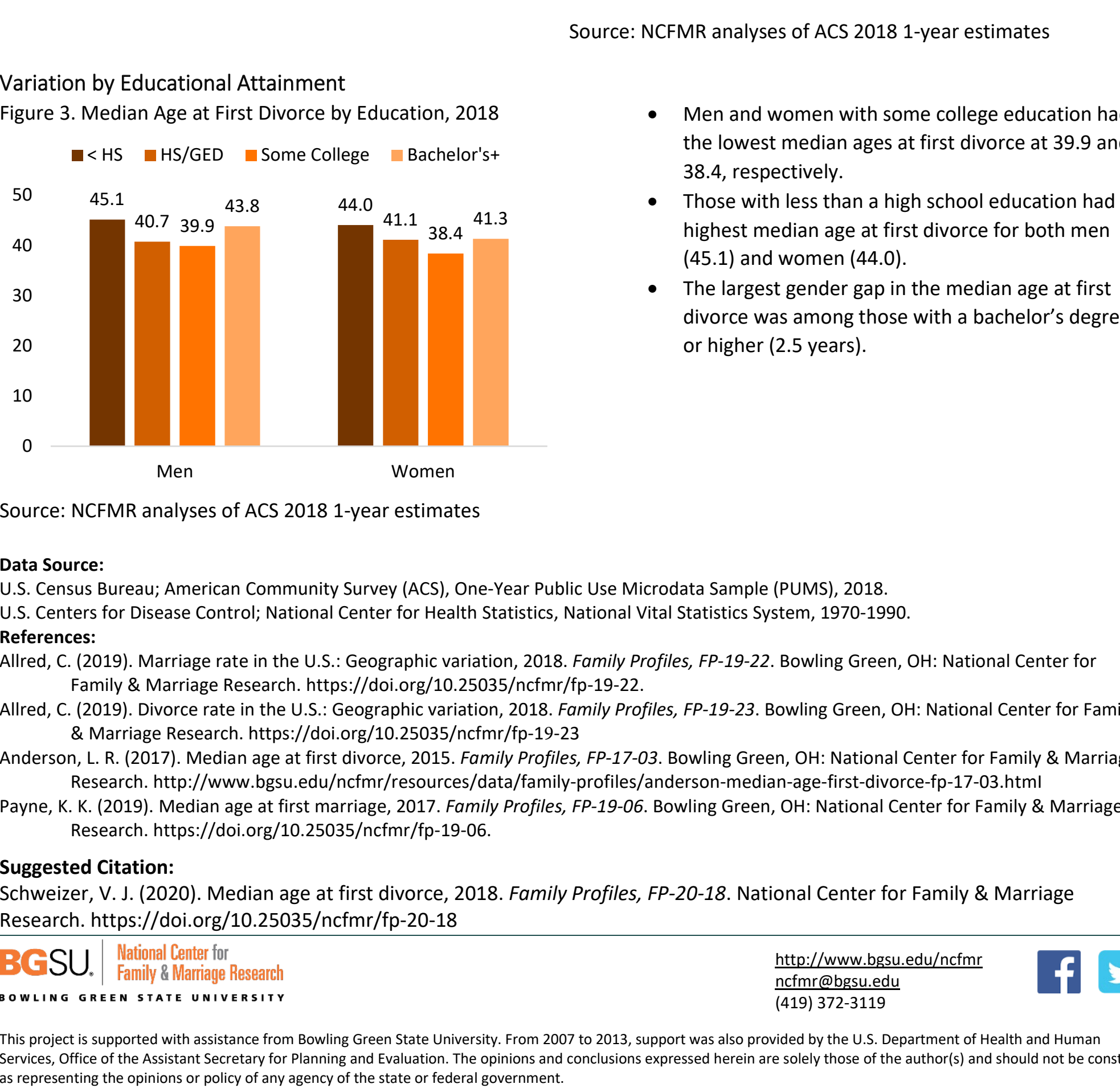

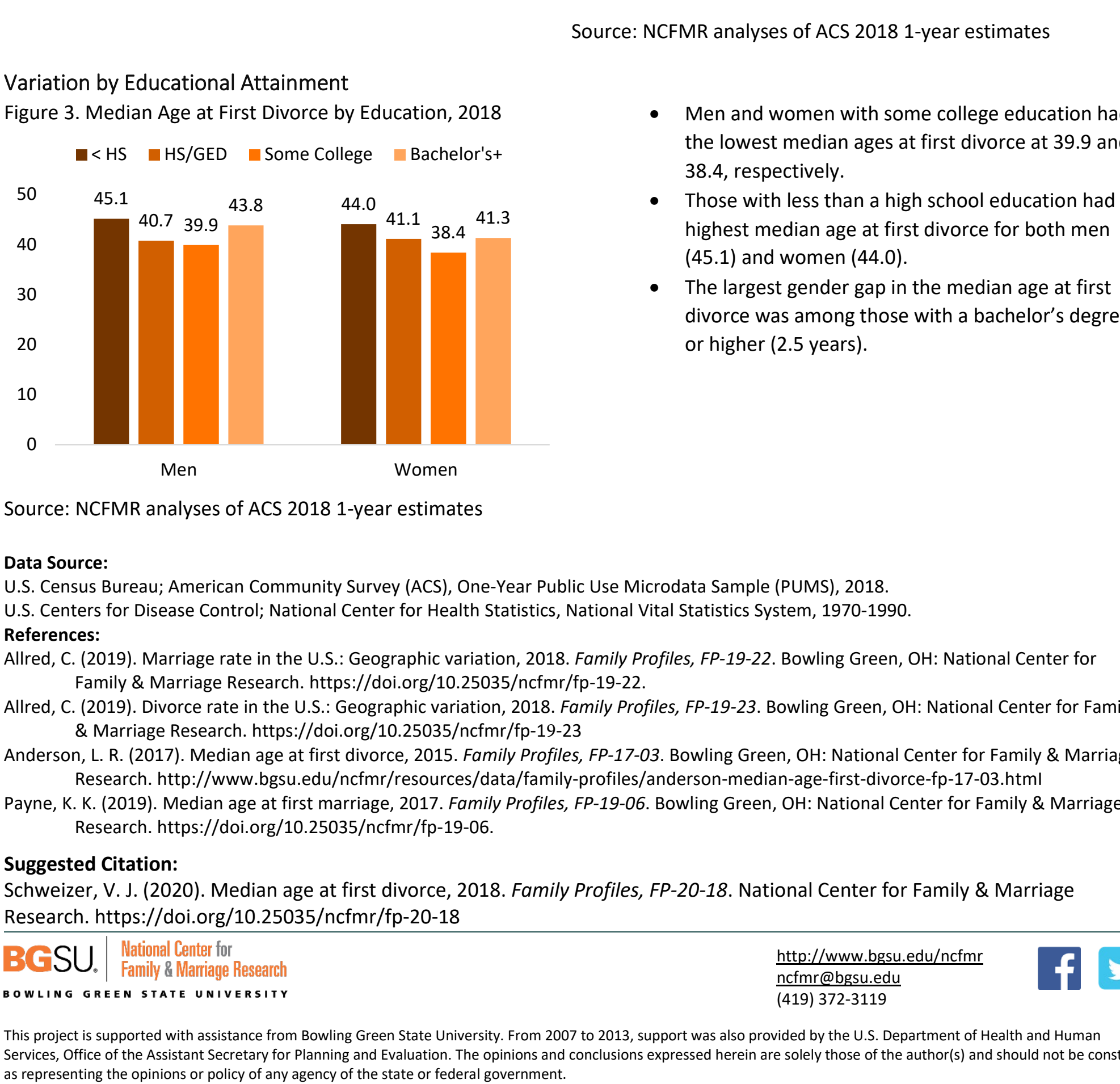

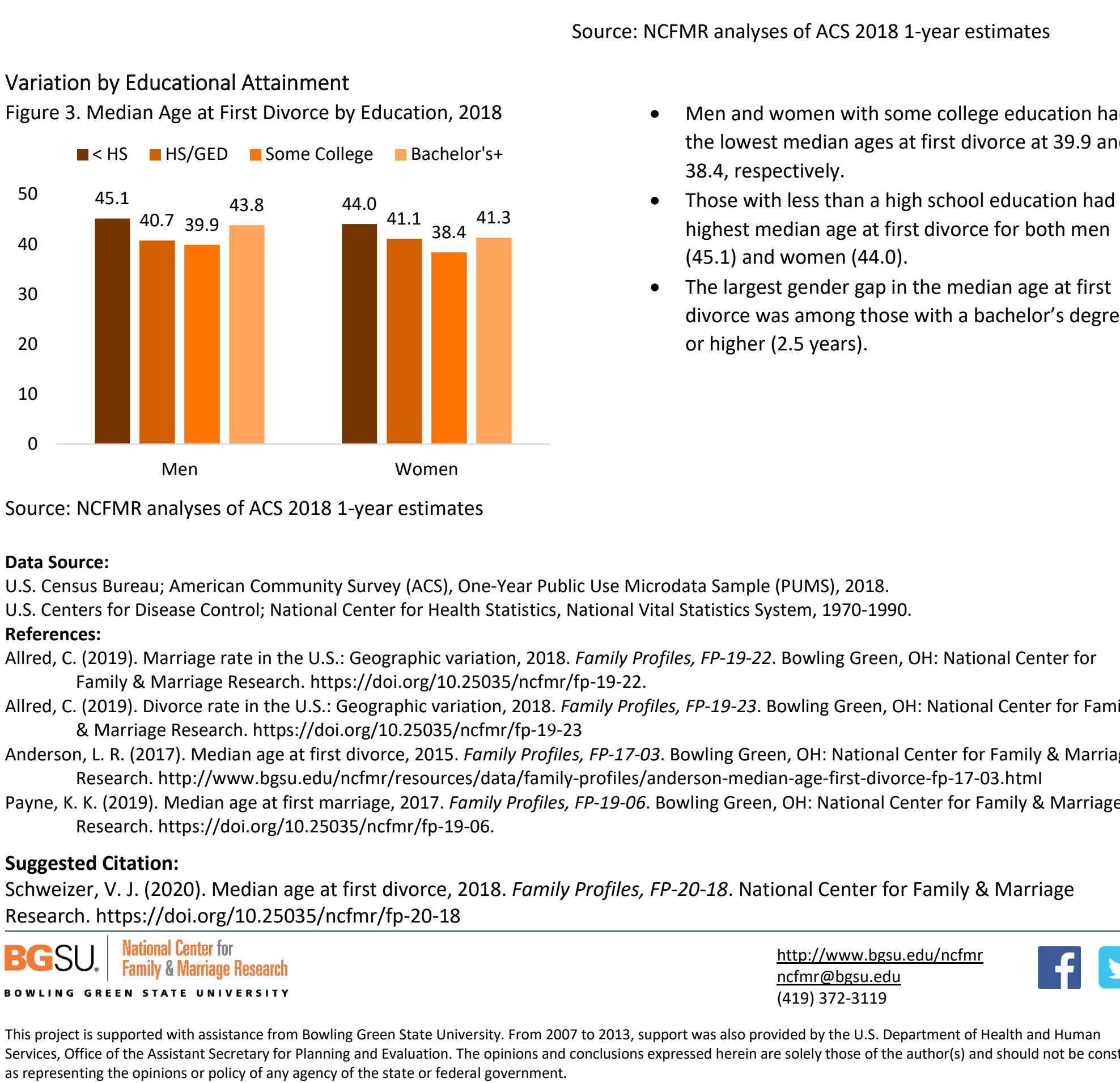

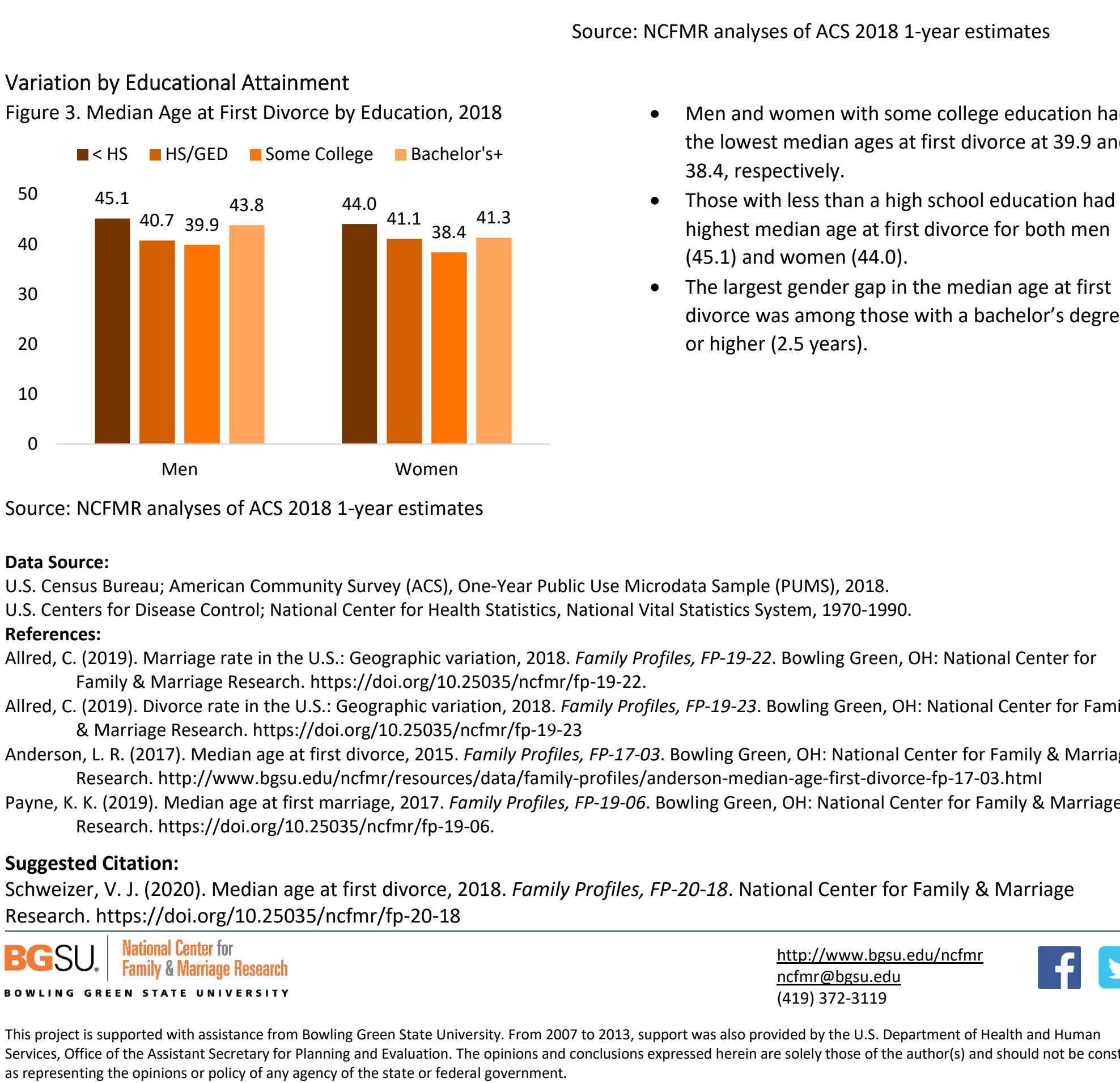$$
\begin{aligned}
& \text { B o w } \\
& \text { This p } \\
& \text { Servic } \\
& \text { as rep }
\end{aligned}
$$

\section{Variation by Race/Ethnicity}

- Asian men and women had the highest median ages at first divorce at 43.7 and 43.2 , respectively.

- Men and women in the 'Other' racial/ethnic groups had the lowest median ages at first divorce at 38.4 for men and 38.3 for women.

- White men and women have the largest gender gap in median ages at first divorce at 2.1 years. All other groups have smaller gender gaps, with nearly the same age at first divorce for women and men.

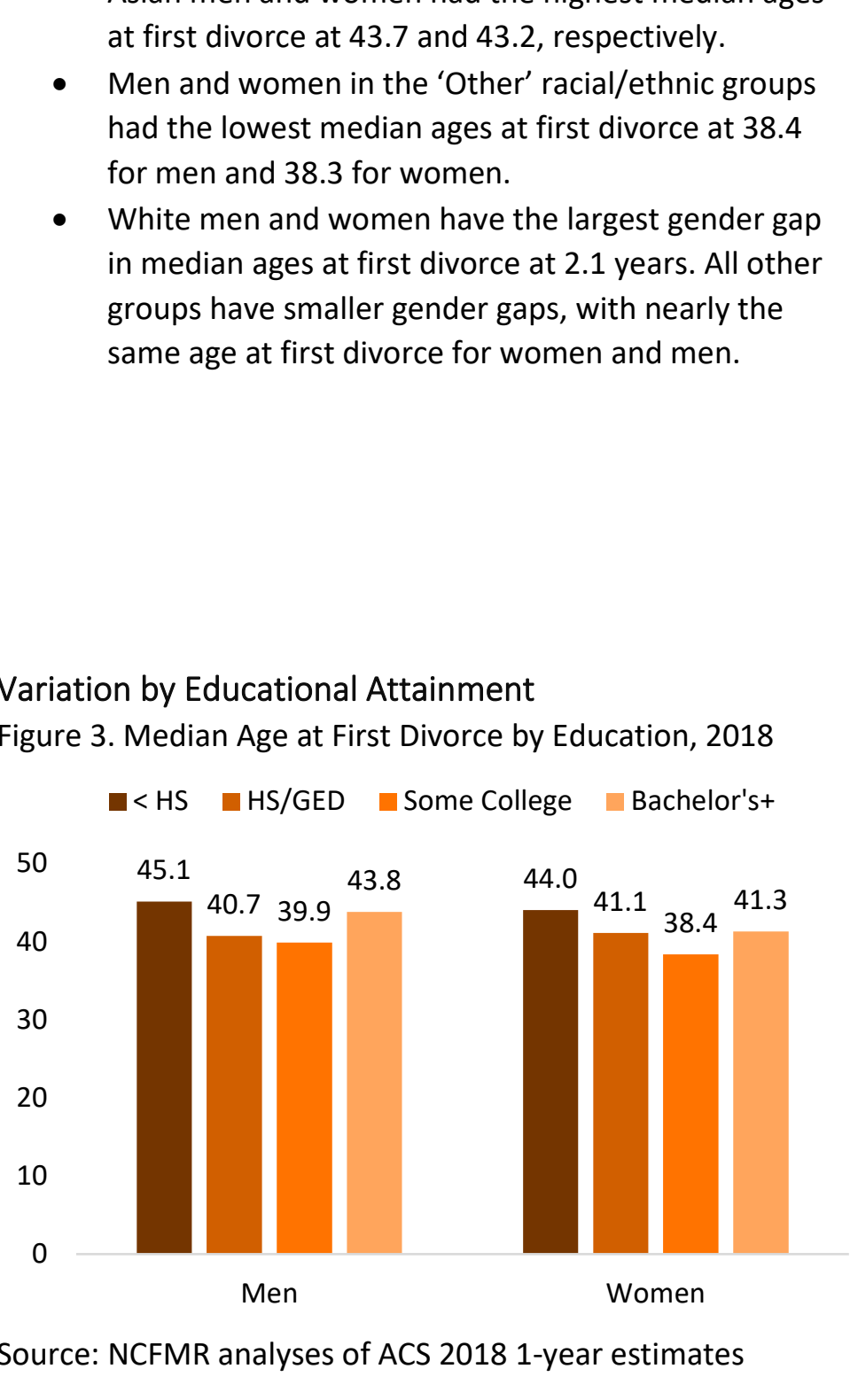

